\title{
C80RF37 Is Required for Photoreceptor Outer Segment Disc Morphogenesis by Maintaining Outer Segment Membrane Protein Homeostasis
}

\author{
๑DAli S. Sharif, ${ }^{1,2}$ ๑Dongmei Yu, ${ }^{1}$ Stuart Loertscher, ${ }^{1}$ Richard Austin, ${ }^{1}$-Kevin Nguyen, ${ }^{1} \odot$ Pranav D. Mathur, ${ }^{1,2}$ \\ Anna M. Clark, ${ }^{1}$ Junhuang Zou, ${ }^{1}$ Ekaterina S. Lobanova, ${ }^{4}$ (DVadim Y. Arshavsky, ${ }^{4}$ and ${ }^{\text {DO Jun Yang }}{ }^{1,2,3}$ \\ ${ }^{1}$ Department of Ophthalmology and Visual Sciences, Moran Eye Center, ${ }^{2}$ Department of Neurobiology and Anatomy, ${ }^{3}$ Department of Surgery, Division of \\ Otolaryngology, University of Utah, Salt Lake City, Utah 84132, and ${ }^{4}$ Albert Eye Research Institute, Duke University, Durham, North Carolina 27710
}

C8ORF37 is a causative gene for three different clinical forms of incurable retinal degeneration. However, the completely unknown function of C8ORF37 limits our understanding of the pathogenicity of C8ORF37 mutations. Here, we performed a comprehensive phenotypic characterization of a C8orf37 K0 mouse line, generated using CRISPR/Cas9 technology. Both C8orf37 KO male and female mice exhibited progressive and simultaneous degeneration of rod and cone photoreceptors but no non-ocular phenotypes. The major ultrastructural feature of $C 8$ orf $37 \mathrm{KO}$ photoreceptors was massive disorganization of the outer segment $(\mathrm{OS})$ membrane discs starting from the onset of disc morphogenesis during development. At the molecular level, the amounts of multiple OS-specific membrane proteins, including proteins involved in membrane disc organization, were reduced, although these proteins were targeted normally to the OS. Considering the distribution of C80RF37 throughout the photoreceptor cell body, the normal structure of the K0 photoreceptor connecting cilium, and the absence of defects in other ciliary organs of the $\mathrm{KO}$ mice, our findings do not support the previous notion that C80RF37 was a ciliary protein. Because C80RF37 is absent in the photoreceptor OS, C80RF37 may participate in the secretory pathway of OS membrane proteins in the photoreceptor cell body and thus maintain the homeostasis of these proteins. This study established a valid animal model for future therapeutic studies of C8ORF37-associated retinal degeneration. This study also shed new light on the role of C80RF37 in photoreceptors and on the pathogenic mechanism underlying retinal degeneration caused by C8ORF37 mutations.

Key words: cone-rod dystrophy; outer segment disc; photoreceptor; retinal degeneration; retinitis pigmentosa

Significance Statement

Inherited retinal degeneration is a group of incurable conditions with poorly understood underlying molecular mechanisms. We investigated C8ORF37, a causative gene for three retinal degenerative conditions: retinitis pigmentosa, cone-rod dystrophy, and Bardet-Biedl syndrome. C8ORF37 encodes a protein with no known functional domains and thus its biological function is unpredictable. We knocked out the C8ORF37 ortholog in mice, which resulted in a retinal phenotype similar to that observed in patients. We further demonstrated that C80RF37 is required for photoreceptor outer segment disc formation and alignment, a process that is critical for photoreceptor function and survival. This study advances our understanding of the pathogenesis of retinal degeneration and establishes a valuable mouse model for future therapeutic development.

\section{Introduction}

Inherited retinal degeneration is a group of heterogeneous diseases affecting primarily photoreceptors. To date, $>250$ genes have been identified as causal factors in inherited retinal degeneration. However, little is known about the function of a significant number of these genes and this knowledge gap hinders the development of effective treatments. C8ORF37, named for its
Received Oct. 14, 2017; revised Jan. 30, 2018; accepted Feb. 5, 2018.

Author contributions:J.Y. designed research; A.S.S., D.Y., S.L., R.A., K.N., P.D.M., A.M.C., J..., and E.S.L. performed research; A.S.S., V.Y.A., and J.Y. analyzed data; A.S.S., V.Y.A., and J.Y. wrote the paper.

This work was supported by the National Eye Institute (Grants EY020853 and EY026521 to J.Y.; Grant EY024234 to A.S.S, Grants EY022959, EY12859, EY05722 to V.Y.A.; and Core Grant EY014800 to the Department of Ophthalmology and Visual Sciences, University of Utah), Research to Prevent Blindness (J.Y. and the Departments of Ophthalmology and Visual Sciences at the University of Utah and Duke University), the University of Utah Research Foundation (incentive seed grant to J.Y.), and the Moran Eye (enter, University of Utah (startup package to J.Y.). The funders had no role in study design, data collection and analysis, decision to publish, or preparation of the manu- script. We thank Wolfgang Baehr (University of Utah), Krzysztof Palczewski (Case Western Reserve University) Robert Molday (University of British Columbia), Tiansen Li (National Eye Institute), Andrew Goldberg (Oakland University), Qin Liu (Harvard Medical School), Amir Rattner (Johns Hopkins University), and Steven Pittler (University of Alabama) for providing antibodies; Robert Marc, Jia-hui Yang, Kevin Rapp, Carl Watt, and Rebecca Pfeiffer (University of Utah) for assistance with TEM; Susan Tamowski (Transgenic Gene Targeting Mouse Core) and Timothy Dahlem (Mutation Generation and Detection Core) for generating (8orf37 K0 mice; and Wolfgang Baehr, Monica Vetter, Yukio Saijoh, and Michael Deans (University of Utah) for insightful comments on the first version of this manuscript. 
position on human chromosome 8 , is a causative gene for autosomal recessive retinitis pigmentosa (RP), cone-rod dystrophy (CRD), and Bardet-Biedl syndrome (BBS) (Estrada-Cuzcano et al., 2012; van Huet et al., 2013; Jinda et al., 2014; Lazar et al., 2014; Ravesh et al., 2015; Heon et al., 2016; Katagiri et al., 2016; Khan et al., 2016; Rahner et al., 2016). RP is the most common inherited retinal degenerative disease (Hartong et al., 2006). Blindness in RP patients results initially from a loss of rod photoreceptors followed by loss of cones. BBS is a syndromic form of RP and is characterized by childhood-onset rod-cone dystrophy, polydactyly, obesity, mental retardation, renal dysfunction, and hypogenitalism (Hartong et al., 2006; Zaghloul and Katsanis, 2009). These phenotypes are due to defects in the primary cilium in various organs. Therefore, BBS is also classified as a ciliopathy. Finally, CRD is characterized by cone-mediated vision impairment followed by rod degeneration or simultaneous degeneration of cones and rods (Thiadens et al., 2012). Currently, no genotypephenotype correlation has been observed in C8ORF37-deficient patients.

The function of the C8ORF37 protein is unknown and cannot be predicted from sequence analysis because it contains no known functional domains or motifs and does not belong to any known protein family. The human C8ORF37 protein has 207 aa. Twothirds of its C-terminal sequence is highly conserved from mammals to unicellular flagellates and oomycetes (Estrada-Cuzcano et al., 2012). As in humans, knock-down of the C8ORF37 ortholog in zebrafish leads to impaired vision (Heon et al., 2016). This evolutionary conservation in sequence and phenotype suggests a functional significance of C8ORF37 in a broad range of species. In hTERT-RPE1 cells, C8ORF37 was localized at the base of the primary cilium and in the cytoplasm and, in mouse photoreceptors, C8ORF37 was found to be enriched at the base of the connecting cilium and along the ciliary rootlet (Estrada-Cuzcano et al., 2012). Furthermore, c8orf37 knock-down in zebrafish causes a reduction in the Kupffer's vesicle, a ciliated organ responsible for left-right body asymmetry establishment during development, and slows retrograde melanosome transport in melanophores (Heon et al., 2016). These phenotypes, combined with the potential localization of C8ORF37 at the ciliary apparatus and its association with BBS, suggest that C8ORF37 might contribute to the function of the primary cilium.

In the retina, the photoreceptor outer segment (OS) is a large specialized primary cilium that harbors phototransduction machinery on tightly stacked membrane discs. The integrity of this organelle and the tight disc alignment are crucial for photoreceptor function and survival (Ding et al., 2004; Zhang et al., 2009; Pearring et al., 2013). OS proteins are synthesized in the photoreceptor inner segment (IS) and transported to their destination during OS morphogenesis and subsequent renewal (Young, 1967). However, the mechanisms underlying the synthesis, sorting, and transport of OS proteins in the IS remain poorly understood (Pearring et al., 2013). In this report, we knocked out the mouse ortholog of C8ORF37 (C8orf37, aka 2610301B20Rik), which produced a retinal phenotype similar to that seen in C8ORF37-deficient patients, but no other BBS phenotypes. We demonstrated that C8ORF37 is distributed throughout photoreceptors except the

The authors declare no competing financial interests.

P.D. Mathur's present address: Department of Research, Otonomy, Inc., San Diego, CA 92121.

Correspondence should be addressed to Dr. Jun Yang, John A Moran Eye Center, University of Utah, 65 Mario Capecchi Dr., Bldg. 523, Salt Lake City, UT 84132. E-mail: jun.yang@hsc.utah.edu.

DOI:10.1523/JNEUROSCI.2964-17.2018

Copyright (c) 2018 the authors $\quad 0270-6474 / 18 / 383161-17 \$ 15.00 / 0$
Table 1. DNA primer information

\begin{tabular}{|c|c|}
\hline Primer name & Primer sequence \\
\hline \multicolumn{2}{|c|}{ CRISPR/Cas9 plasmid construction } \\
\hline C8-E1-S1-F & CACCGCGTCTGTTCAAGATGGCGA \\
\hline C8-E1-S1-R & AAACTCGCCATCTTGAACAGACGC \\
\hline C8-E5-S10-F & CACCGCTCACTATCCGGAAATCAC \\
\hline C8-E5-S10-R & AAACGTGATTTCCGGATAGTGAGC \\
\hline \multicolumn{2}{|c|}{$\begin{array}{l}\text { HRMA analysis and genotyping for }\left(80 \mathrm{or} 37^{\mathrm{ex1} / \mathrm{ex} 1}\right. \\
\text { and }\left(80 \mathrm{orf3} 7^{\text {ex5/ex5 }}\right.\end{array}$} \\
\hline FWD1.1-Exon1 & GTTGCCGTGGAAACCACCGGCC \\
\hline RVS1.1-Exon1 & CCAGCCTCAAGGGGTCGAGTCTGC \\
\hline FWD5.1-Exon5 & TCTCTCTGAGCAGAGCATGTGA \\
\hline RVS5.1-Exon5 & GGCGAAACTCTTCAGAAACATACC \\
\hline \multicolumn{2}{|c|}{ Genotyping for C8orf37 del/del } \\
\hline FWRDEX1 & GCTCCCGGGCGCGTCGGTTTC \\
\hline FWRDEX5 & GCCCTACCTGGCTTAGAACTCAC \\
\hline RVSEX5 & CAAGGAGGTTCCCGAGCAAACATC \\
\hline \multicolumn{2}{|c|}{ C8orf37 cDNA cloning } \\
\hline FWRD & ATGGCGAAGGACCTGGA \\
\hline RVSs & TCAGTGTTTACCACACACCCA \\
\hline \multicolumn{2}{|l|}{ gRT-PCR } \\
\hline FWD-rhodopsin & GGCGGAACCATGGCAGTTCTCC \\
\hline RVS-rhodopsin & CCACCAGGGACCACAGGGC \\
\hline FWD-S-opsin & СCCTCGGGGGCTTCCTCTTCTG \\
\hline RVS-S-opsin & GGGTGGGATGGACACCCCG \\
\hline FWD-M-opsin & GGACTTGTGCTGGCAGCCACC \\
\hline RVS-M-opsin & GACGATTCCCACAGTGGCCAGC \\
\hline GC1FWD & GGGCTCACGATGCGGTGC \\
\hline GC1RVS & GCACAAAGGAGGGCTCCTCGG \\
\hline PRPH2FWD & CAACGGCTTCCGGGACTGG \\
\hline PRPH2RVS & GACGAGAAGTGTGACGACGCCC \\
\hline GAPDH_F & CCAGGAGCGAGACCCCACTA \\
\hline GAPDH $R$ & TGGTCATGAGCCCTTCCACA \\
\hline
\end{tabular}

OS and is required for maintaining normal amounts of OS membrane proteins and normal OS disc alignment. Our results suggest that C8ORF37 may function through its involvement in membrane protein turnover, but not transport.

\section{Materials and Methods}

Animals. C8orf37 KO mice were generated using the CRISPR/Cas9 approach at the Transgenic and Gene Targeting Mouse Core and the Mutation Generation and Detection Core, University of Utah. Small guide RNA sites targeting exon 1 and exon 5 of C8orf 37 and compatible with the U6 promoter (see Fig. $1 A$ ) were identified using ZiFit Targeter (version 4.2) (Sander et al., 2007, 2010; Hwang et al., 2013; Mali et al., 2013), with potential off targets analyzed using CasOT (http://casot.cbi. pku.edu.cn/; Xiao et al., 2014). Pairs of oligonucleotides corresponding to the chosen small guide RNA sites (Table 1) were synthesized, annealed, and cloned into the pX330-U6-Chimeric_BB-CBh-hSpCas9 vector, a gift from Feng Zhang (Addgene plasmid \#42230), according to the protocol detailed in Cong et al. (2013). Both CRISPR/Cas9 plasmids targeting exon 1 and exon 5 were simultaneously injected into F1 mouse embryos (CBA/C57BL6, confirmed to be free of $\mathrm{Crb}^{\mathrm{rd}}{ }^{\mathrm{rd}}$ allele) at a concentration of 5,25 , or $50 \mathrm{ng} / \mu \mathrm{l} . \mathrm{F}_{0}$ founder mice were screened by high-resolution melting analysis (HRMA; LightScanner instrument, Biofire Diagnostics) using the primers listed in Table 1 . Three $\mathrm{F}_{0}$ founder mice carrying deletions in exon 1 , exon 5 , and between exons 1 and 5 were crossed with C57BL/6 mice (The Jackson Laboratory) to achieve germline transmission. C8orf $37^{\text {ex1/ex1 }}, C 8$ orf $37^{\text {ex5/ex5 }}$, and C8orf $37^{\mathrm{del} / \mathrm{del}}$ mouse lines were established. The exact mutations in their genomes were revealed by sequencing of the PCR products containing the mutations. The three C8orf 37 mutant mouse lines were then maintained and examined according to the protocol approved by the Institutional Animal Care and Use Committee at the University of Utah. Routine genotyping was performed by PCR of genomic DNA (all mutant lines) followed by DNA sequencing (C8orf $37^{\mathrm{ex1} / \mathrm{ex} 1}$ and C8orf $37^{\mathrm{ex} 5 / \mathrm{ex} 5}$ only; See Table 1 for 
primer information). Female Long-Evans rats (P50-P60) were purchased from Charles River Laboratories and handled according to the protocol approved by the Institutional Animal Care and Use Committee at Duke University. For terminal experiments, mice or rats were euthanized by $\mathrm{CO}_{2}$ inhalation, consistent with the recommendations of the Panel on Euthanasia of the American Veterinary Medical Association.

Antibodies. Full-length C8orf37 cDNA (NM_026005) was cloned from mouse retinas by RT-PCR into pET28 (Millipore) and pGEX4t-1 (GE Healthcare Life Sciences) vectors for fusion with His and GST tags, respectively (see Table 1 for primer sequences). These two C8orf37 constructs were transformed into BL21-CodonPlus (DE3)-RIPL cells (Agilent Technologies) to generate recombinant proteins. His-tagged C8ORF37 protein was purified from the inclusion body after IPTG induction using Ni-NTA agarose (Qiagen) in the presence of $6 \mathrm{M}$ urea or guanidine. The purified His-C8ORF37 protein was used as an antigen to immunize three rabbits and a chicken (Cocalico Biologicals). GSTtagged C8ORF37 protein was purified from the soluble fraction of cell lysates using GST•Bind resin (Millipore). The His-C8ORF37 and GSTC8ORF37 proteins were immobilized separately to agarose beads using AminoLink Plus Immobilization kit (Pierce Biotechnology). The immobilized His-C8ORF37 was used to affinity purify the sera obtained from one rabbit and one chicken and the immobilized GST-C8ORF37 was used to affinity purify the sera from two rabbits. The specificity of the C8ORF37 antibodies was verified by immunoblot analysis using C8orf37 $\mathrm{KO}$ retinas as a negative control.

Mouse monoclonal antibody against rhodopsin (1D4, RRID:AB_2315272); chicken antibodies against $\mathrm{S}$ - and $\mathrm{M}$-opsins, rootletin, and PRPH2; and sheep antibody against phosducin (PDC) were described previously (Liu et al., 2004; Sokolov et al., 2004; Yang et al., 2005). Mouse monoclonal antibodies against GC1 (GC 2H6), PRPH2 (Per 5H2), CNGA1 (PMC 1D1), and GARP2 (GARP 4B1) were gifts from Robert Molday (University of British Columbia). Mouse monoclonal antibody against GC1 (1S4) and rabbit antibodies against GC2 (L-670), GCAP1 (UW14 and UW101), GCAP2 (UW50), and arrestin were gifts from Wolfgang Baehr (University of Utah) and Krzysztof Palczewski (Case Western Reserve University). Rabbit antibodies against PRPH2, PCDH21, and CNGB1 were gifts from Andrew Goldberg (Oakland University), Amir Rattner (Johns Hopkins University), and Steven Pittler (University of Alabama), respectively. Chicken antibody against RP1 was a gift from Qin Liu (Harvard Medical School). Mouse monoclonal antibodies against acetylated $\alpha$-tubulin (6-11B-1), $\beta$-tubulin (D66, RRID:AB_477556), $\gamma$-tubulin (GTU-88, RRID:AB_532292), and FLAG (M2, RRID:AB_439685) were purchased from Sigma-Aldrich. Goat antibody against ABCA4 (M-18, RRID:AB_2220287) and rabbit antibody against rod transducin $\alpha$ subunit (K-20, RRID:AB_2294749) were from Santa Cruz Biotechnology. Rat monoclonal antibody against prominin 1 (13A4) and rabbit antibody against rod PDE6 (MOE) were from Affymetrix and CytoSignal, respectively. Rhodamine-labeled peanut agglutinin (RRID:AB_2336642), chicken antibody against M-opsin (PA1-9517, RRID:AB_1077349), and rabbit antibody against S-opsin (NBP1-P20194, RRID:AB_1642989) were from Vector Laboratories, Thermo Fisher Scientific, and Novus Biologicals, respectively. Alexa Fluor-conjugated secondary antibodies and Hoechst dye 33342 were obtained from Invitrogen. Horseradish peroxidase-conjugated secondary antibodies were purchased from Jackson ImmunoResearch Laboratories.

$q R T-P C R$. Retinal total RNA was purified from $C 80 r f 37^{+/ \text {del }}$ and C8orf $37^{\text {del/del }}$ mice using the SurePrep RNA purification kit (Fisher Scientific) and subjected to RT using the ThermoScript RT-PCR system (Invitrogen). qRT-PCR analyses for rhodopsin, M-opsin, S-opsin, GC1, PRPH2, and GAPDH were performed from the above RT reactions using SYBR Premix Ex Taq kit (TakaRa) and the CFX Connect real-time PCR machine (Bio-Rad) according to the manufacturers' instructions. Primer sequence information is listed in Table 1 . The thermal cycle was set at $95^{\circ} \mathrm{C}$ for $2 \mathrm{~min}$ followed by 45 cycles of $95^{\circ} \mathrm{C}$ for $10 \mathrm{~s}$ and $55^{\circ} \mathrm{C}$ for $30 \mathrm{~s}$. Cq values were determined using the single threshold mode of CFX Manager software. The expression levels of rhodopsin, M-opsin, S-opsin, GC1, and PRPH2 mRNAs were first normalized by that of GAPDH using the formula $E^{\mathrm{Cq} \text { sample-Cq GAPDH }}$, where $E$ is the efficiency of primer and probe set and equals 2 and $C_{\mathrm{q}}$ sample is the $C_{\mathrm{q}}$ of rhodopsin, M-opsin,
S-opsin, GC1, or PRPH2. The expression levels of rhodopsin, M-opsin, S-opsin, GC1, and PRPH2 were further normalized by the mean of C8orf $37^{+/ \text {del }}$ group before statistical analysis.

Cell culture, transfection, immunostaining, and immunoblot analyses. IMCD3 cells (RRID:CVCL_0429) were cultured according to the ATCC protocol and transfected by Lipofectamine 2000 Transfection Reagent (Invitrogen). GFP-tagged C8ORF37 DNA construct was made by inserting mouse C8ORF37 full-length cDNA (NM_026005) into pEGFP-C1 plasmid (Clontech Laboratories). Retinal in vivo transfection (Matsuda and Cepko, 2004) and immunostaining of cultured cells and mouse retinal sections (Wang et al., 2012) were conducted as described previously. To quantify S/M-opsin mislocalization in the retina, immunostaining using mixed chicken S- and M-opsin antibodies (Yang et al., 2005) was conducted. Cone photoreceptors with S/M-opsin immunostaining signals mislocalized in the IS, outer nuclear layer (ONL), or synaptic terminus were counted in a region of retinal cross-sections, which was $211 \mu \mathrm{m}$ wide and $\sim 900 \mu \mathrm{m}$ away from the optical nerve head. The total number of cone photoreceptors in the same region was estimated by the number of cone OS with S/M-opsin signals. These two numbers were used to calculate the percentage of cone photoreceptors with mislocalized opsins.

Serial tangential sectioning of rat retinas at $20 \mu \mathrm{m}$ and immunoblot analysis of proteins in the serial sections were performed according to the procedure reported previously (Lobanova et al., 2008). Other immunoblot analyses were performed using our previous procedure (Wang et al., 2012) except that protein samples were incubated at $37^{\circ}$ for $30 \mathrm{~min}$ instead of boiling for $10 \mathrm{~min}$. Immunoblotting of S/M-opsins was conducted using a mixture of chicken S- and M-opsin antibodies (Yang et al., 2005), commercial chicken M-opsin antibody, or commercial rabbit S-opsin antibody. The intensity of immunoblot signals was quantified by ImageJ using the "Gels" feature under the "Analyze" menu. The intensity of the bands of interest was normalized by the intensity of loading control bands (e.g., $\gamma$-tubulin) in the same lanes on the same blots except for the analysis of protein expression during postnatal development, which was compared with $\gamma$-tubulin protein expression in the same set of samples.

Electroretinogram (ERG) and spectral domain optical coherence tomography (SD-OCT). ERG tests were performed using a UTAS-E3000 instrument (LKC Technologies) as described previously (Zou et al., 2011). After dark adaptation overnight, mice were anesthetized by intraperitoneal injection of ketamine and xylazine $(0.1 \mathrm{mg}$ and $0.01 \mathrm{mg} / \mathrm{g}$ body weight, respectively) and pupils were dilated with $1 \%$ tropicamide. Full-field scotopic retinal electrical responses were recorded in the dark upon a series of white light stimuli at increasing intensities. Full-field photopic retinal electrical responses were subsequently recorded after light adaptation at $33.25 \mathrm{~cd} / \mathrm{m}^{2}$ for $10 \mathrm{~min}$. The a-wave amplitude of scotopic ERGs was measured from the baseline to the peak of the cornea-negative wave and the b-wave amplitude of scotopic and photopic ERGs was measured from the peak of the cornea-negative wave to the peak of the major cornea-positive wave. The implicit times of a- and b-waves were measured from the onset of the light stimulus to the peaks of a- and b-waves, respectively.

SD-OCT images were acquired from anesthetized mice using a Spectralis HRA + OCT instrument (Heidelberg Engineering), with super luminescence diode light at an average wavelength of $870 \mathrm{~nm}$. Crosssectional two-dimensional B-scans of $1536 \mathrm{~A}$-scans $(5.3 \mathrm{~mm}$ ) were captured with a rate of $40 \mathrm{kHz}$ and a scan depth of $1.9 \mathrm{~mm}$ at the high-resolution mode. Measurement of retinal thickness was conducted using the analysis tool of Heidelberg Eye Explorer software platform (version 6.0.12.0).

Histology, transmission electron microscopy (TEM), and scanning electron microscopy (SEM). Mouse eye cups, with the anterior segments and lens removed, were fixed overnight in $1 \%$ formaldehyde and $2.5 \%$ glutaraldehyde in $0.1 \mathrm{M}$ cacodylate buffer, $\mathrm{pH}$ 7.5. After washing with $0.1 \mathrm{M}$ cacodylate buffer, the eye cups were postfixed in $2 \%$ osmium tetroxide, dehydrated through a graded alcohol series, and embedded in Epon. Half-micron cross-sections were stained with $1 \%$ methylene blue/azure II or $1 \%$ toluidine blue. The thicknesses of the OS and ONL layers were measured along the retinal vertical meridian at three evenly spaced locations on each side of the optic nerve head. The subsequent procedures for TEM were described previously (Yang et al., 2002). For SEM, retinas were 
dissected and fixed in $2.5 \%$ glutaraldehyde/PBS overnight. After washing in PBS buffer, the retinas were postfixed by alternative incubations in $1 \%$ osmium tetroxide (40 $\mathrm{min}, 3 \times)$ and $0.3 \%$ thiocarbohydrizide (10 min, $2 \times)$. The retinas were then dehydrated with a graded alcohol series, critical point dried using hexamethyldisilazane, and examined using a Hitachi 4800 SEM. OS density was calculated by the number of the OS divided by the retinal tangential width occupied by the OS. OS thickness was calculated by averaging the diameters measured from the top, middle, and bottom of the same OS. OS uniformity was calculated as the difference between the smallest and largest diameters of the same OS.

Experimental design and statistical analyses. All experiments were designed to detect phenotypic differences between C8orf37 homozygous and control (wild-type/heterozygous) groups. Two to four female or male mice each group were examined for their body weight (see Fig. 2A). Two to nine female and male mice per group were tested for scotopic and photopic ERG responses (see Fig. 3C,D). Four to six female and male mice per group were analyzed for their retinal histology (see Fig. $4 B, D$ ). The photoreceptor morphology was examined in three female and male mice per group by SEM (see Fig. 5D). Protein expression levels were compared in four female and male mice each group at P30 or P49 (see Fig. 7). During postnatal development, the protein (see Fig. 8C) and mRNA (see Fig. $8 D$ ) expressions of OS membrane proteins were examined in three to four and two to five female and male mice per group, respectively. Finally, four mice each group were examined to analyze the cone opsin mislocalization (see Fig. 10J). The exact animal numbers used in each experiment can be found in figures and figure legends. All measurements in this study were conducted by an individual who was blinded to genotype. GraphPad PRISM version 5 (RRID:SCR_002798) was used for two-way ANOVA, Bonferroni post tests and Student's $t$ tests. Ordinary two-way ANOVA was conducted for body weight, ERG, and OS membrane protein expression to analyze genotype effect at multiple time points or light intensities (see Figs. $2 A, 3 C, D, 8 C$ ). Repeatedmeasures two-way ANOVA was conducted for retinal thickness, OS length, ONL thickness, and OS membrane protein mRNA level to analyze genotype effect at multiple retinal positions and time points (see Figs. $4 B, D, 8 D$ ). Bonferroni post-tests were conducted after two-way ANOVA to discover at which time points, retinal positions or light intensities the difference between genotype groups occurred. Student's $t$-tests (unpaired and two-tailed) were performed to analyze photoreceptor OS morphology, OS membrane protein expression and opsin mislocalization between genotype groups at single time points (see Figs. 5D, 7; $\mathrm{S} / \mathrm{M}$-opsin in Figs. $8 \mathrm{C}, 10 \mathrm{~J}) . p<0.05$ was considered to indicate a significant difference between the values from different genotype groups.

\section{Results}

\section{Generation of C8orf37 KO mice using CRISPR/Cas9 technology}

We cloned two CRISPR/Cas9 plasmids carrying small guide RNA sequences targeting exon 1 and exon 5 of the mouse C8orf37 gene, respectively (Fig. 1A). To increase mutagenesis efficiency, these two plasmids were injected simultaneously into $349 \mathrm{~F} 1$ zygotes from CBA/C57BL mice. Among the 71 screened founder mice, 32 exhibited INDEL mutations in exon 1; 10 showed INDEL mutations in exon 5; and 7 had a deletion of an $\sim 12$-kb genomic DNA fragment between exons 1 and 5. Through crossing with C57BL/6 mice, three homozygous mutant mouse lines were established: C8orf $37^{\text {ex1/ex1 }}, C 8$ orf $37^{\text {ex } 5 / \text { ex } 5}$, and C8orf $37^{\text {del/del }}($ Fig. $1 B-D)$. All of them were free of $C r b 1^{\text {rd8 }}$ allele. The $C 80 r f 37^{\text {ex1/ex1 }}$ mouse carried a 6 bp deletion including the ATG translation start codon in exon 1; the C8orf $37^{\mathrm{ex} 5 / \mathrm{ex} 5}$ mouse had a 10 bp deletion in exon 5 ; and the $C 80 r f 37^{\mathrm{del} / \mathrm{del}}$ mouse was missing a large genomic fragment between exons 1 and 5, which also included the translation start codon. Immunoblot analysis using both custom-made rabbit and chicken antibodies demonstrated the absence of C8ORF37 fulllength or truncated proteins in all three C8orf37 mutant retinas (Fig. $1 E$ and data not shown), indicating that $C 80 r f 37^{\mathrm{ex} 1 / \mathrm{ex} 1}$, C8orf $37^{\mathrm{ex} 5 / \mathrm{ex} 5}$, and C8orf $37^{\mathrm{del} / \mathrm{del}}$ mice were C8orf37-null. Be- cause nonsense-mediated decay has been reported previously in a patient with a C8ORF37 nonsense mutation (Heon et al., 2016), it might be the reason for the absence of a C8ORF37 truncated protein fragment in $C 80 r+37^{\mathrm{ex} 5 / \mathrm{ex} 5}$ mice. In addition, the C8ORF37 protein level in $C 8$ orf $37^{+/ \text {ex } 5}$ and $C 8$ orf $37^{+/ \text {del }}$ retinas was similar to that in $\mathrm{C} 8 \mathrm{orf} 37^{+/+}$retinas (Fig. $1 E$ ), which probably explains the recessive inheritance of C8ORF37-associated diseases (EstradaCuzcano et al., 2012; van Huet et al., 2013; Jinda et al., 2014; Lazar et al., 2014; Ravesh et al., 2015; Heon et al., 2016; Katagiri et al., 2016; Khan et al., 2016; Rahner et al., 2016).

C8orf $37^{\text {ex1/ex1 }}, C 80 r f 37^{\text {ex5/ex5 }}$, and C8orf $37^{\text {del } / \text { del }}$ mice were viable and indistinguishable from their wild-type littermates in reproductive performance and general health. Specifically, male and female mice from the three KO lines showed normal body weights compared with their heterozygous littermates up to 6 months of age (Fig. 2A). In C8orf $37^{\text {del/del }}$ mice, no defects were observed in forelimb and hindlimb digit numbers (Fig. 2B, $n=$ $\sim 70$ mice at various ages), kidney morphology and weight (Fig. $2 C, n=9$ mice at P28-P60), or left-right body asymmetry ( $n=$ 23 mice at $\mathrm{P} 0-\mathrm{P} 4)$. Therefore, the three C8orf $37 \mathrm{KO}$ mouse lines did not appear to have the non-ocular phenotypes that are manifested in BBS patients.

\section{Abnormal retinal function of $\mathrm{C} 8 \mathrm{orf} 37 \mathrm{KO}$ mice}

To assess the retinal function of C8orf $37^{\text {ex1/ex1 }}, C 8 o r f 37^{\text {ex5/ex5 }}$, and $C 8$ orf $37^{\mathrm{del} / \mathrm{del}}$ mice, we performed ERG. At 5 weeks of age, the scotopic and photopic ERG responses of C8orf $37^{+/ \text {exl }}$, C8orf $37^{+/ \text {ex } 5}$, and $\mathrm{C} 8$ orf $37^{+/ \text {del }}$ mice were similar to those of $\mathrm{C} 8$ orf $37^{+/+}$mice (Fig. $3 C$, top row), consistent with the normal expression level of C8ORF37 protein in these heterozygous mutant mice (Fig. 1E). Therefore, in the following experiments, we compared the phenotypes of C8orf37-null mice with their corresponding heterozygous littermates. In all three C8orf37-null mice at 5 weeks of age, the amplitudes of scotopic ERG a- and b-waves (Fig. $3 A, C$ ) and the amplitude of the photopic ERG b-wave (Fig. 3B,C) were reduced by $\sim 60 \%\left(F_{(6,148)}=54.41, p<0.0001\right.$, two-way ANOVA $), 45 \%$ $\left(F_{(6,148)}=22.35, p<0.0001\right.$, two-way ANOVA $)$, and $35 \%\left(F_{(6,114)}=\right.$ 20.85, $p<0.0001$, two-way ANOVA), respectively, at various light intensities. At 12 weeks of age, the amplitudes of scotopic ERG a- and b-waves and the amplitude of the photopic ERG b-wave were further reduced by $\sim 75 \%\left(F_{(5,98)}=61.61, p<\right.$ 0.0001 , two-way ANOVA), $55 \%\left(F_{(5,98)}=46.66, p<0.0001\right.$, two-way ANOVA $)$, and $50 \%\left(F_{(5,74)}=14.58, p<0.0001\right.$, twoway ANOVA), respectively (Fig. $3 C$, middle row). At the same age, the implicit time of the scotopic ERG a-wave became prolonged at 1.38 and $2.38 \mathrm{lg} \mathrm{cds} / \mathrm{m}^{2}\left(F_{(5,98)}=8.95, p<0.0001\right.$, two-way ANOVA), whereas the implicit times of scotopic and photopic ERG b-waves were generally normal (Fig. 3C, bottom row). These findings demonstrated that both rods and cones are affected by the $\mathrm{KO}$ of C8orf37. The similar changes in ERG responses in the three $\mathrm{KO}$ lines suggest that the ERG phenotype is caused specifically by the loss of C8orf 37 , but not by any random off-target mutations, which is a general concern when using CRISPR/Cas9 genome engineering technology.

Because the genotyping procedure was simpler for $C 8$ orf $37^{\mathrm{del} / \mathrm{del}}$ mice than for $C 80 r f 37^{\text {exl/ex1 }}$ and $C 8$ orf $37^{\text {ex5/ex5 }}$ mice, we next only focused on phenotypic characterization of C8orf $37^{\mathrm{del} / \mathrm{del}}$ mice. C8orf $37^{\mathrm{del} / \mathrm{del}}$ mice exhibited reduced scotopic and photopic ERG responses as early as 3 weeks of age, the earliest time point at which reliable ERG responses can be recorded $\left(F_{(1,38)}=160.9\right.$, $p<0.0001$ for scotopic a-wave; $F_{(1,38)}=58.48, p<0.0001$ for scotopic b-wave; $F_{(1,33)}=48.19, p<0.0001$ for photopic b-wave, two-way ANOVA; Fig. 3D). In addition, the reduction of scotopic 

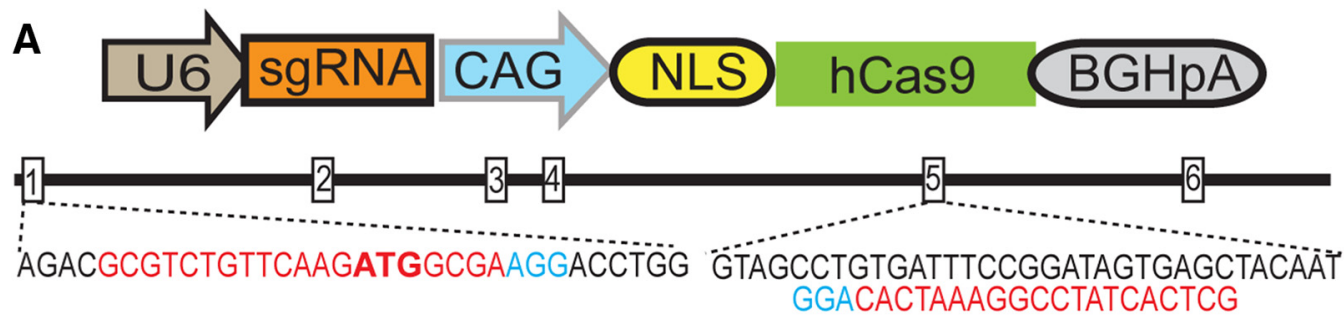

B Exon 1 mutation
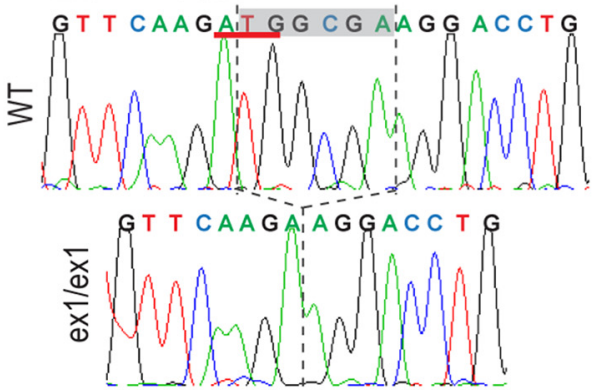

D Deletion between exons $1 \& 5$

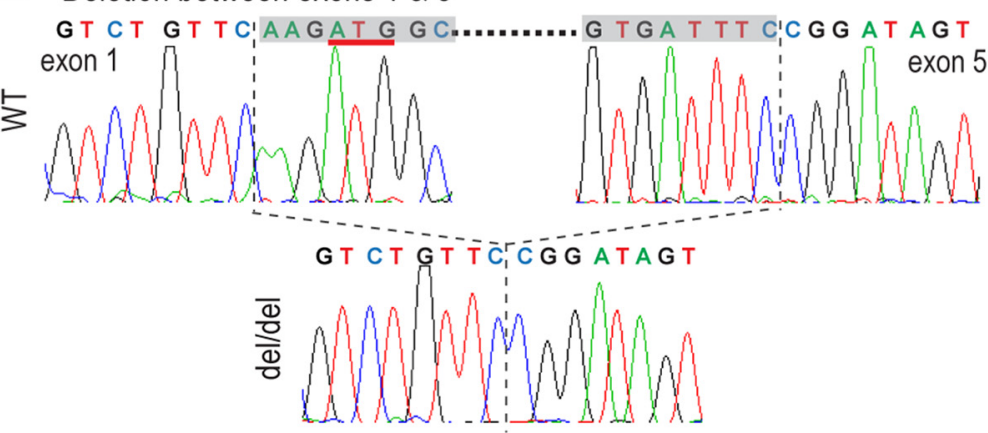

C Exon 5 mutation

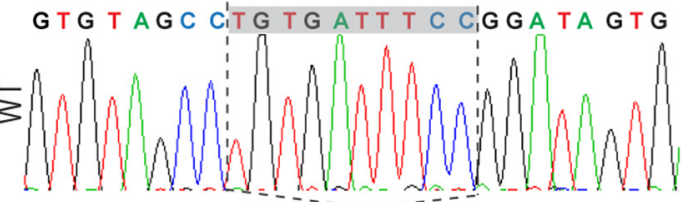

G T G TAGCC,
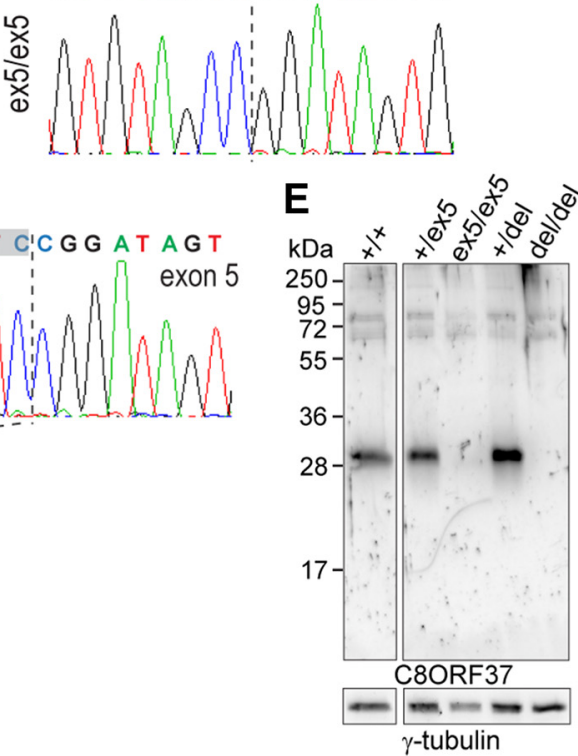

Figure 1. Generation of C8orf37 KO mice. A, Packaging of small guide RNA (sgRNA) and Cas9 in pX330-U6-Chimeric_BB-CBh-hSpCas9 vector (top). The sequence and target position of sgRNAs used in this study are shown at the bottom. Rectangles labeled with numerals denote mouse C8orf37 exons. U6, U6 Promoter; CAG, a hybrid of the cytomegalovirus early enhancer element and chicken $\beta$-actin promoter; NLS, nuclear localization signal; and BGHpA, bovine growth hormone polyadenylation signal. $\boldsymbol{B}$ - D, DNA sequencing chromatograms of wild-type and $(80$ orf37 mutant mice for 8 orf3 $7^{\text {ex1/ex1 }}(\boldsymbol{B})$, C $80 r f 37^{\text {ex5/ex5 }}(\boldsymbol{C})$, and $\left(80 r f 37^{\text {del/del }}(\boldsymbol{D})\right.$ alleles. Deleted regions in these three mutant alleles are highlighted in gray. Translation start codons are underlined in red.

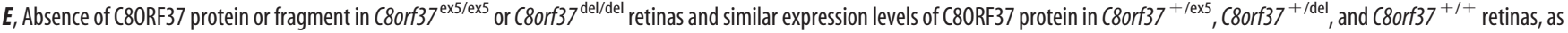
shown by immunoblot analysis at 1 month of age. $\gamma$-tubulin was used as a loading control.

ERG a-wave and photopic ERG b-wave amplitudes was progressive up to 26 weeks of age, the latest time point examined (Fig. $3 D)$. The prolongation of scotopic ERG responses appeared to be relatively stationary from $12-26$ weeks of age $\left(F_{(1,40)}=22.12, p<\right.$ 0.0001 for scotopic a-wave at $1.38 \mathrm{lg} \mathrm{cds} / \mathrm{m}^{2}$, two-way ANOVA) and the prolongation of photopic ERG responses emerged at 26 weeks of age $\left(F_{(1,34)}=11.33, p=0.0019\right.$ for photopic b-wave at $1.38 \mathrm{lg} \mathrm{cds} / \mathrm{m}^{2}$, two-way ANOVA). Therefore, the dysfunction of rods and cones occurred simultaneously and was progressive in C8orf37 KO mice.

\section{Retinal degeneration in C8orf37 $\mathrm{KO}$ mice}

To investigate whether C8orf37 KO led to retinal degeneration, which is characterized by photoreceptor cell loss, we conducted noninvasive SD-OCT and histological analysis of retinal plastic sections. SD-OCT analysis showed that 2-month-old C8orf37 ${ }^{\mathrm{del} / \mathrm{del}}$ mice lost the photoreceptor IS/OS junction line (Fig. 4A), which is an indicator of retinal abnormality (Mitamura et al., 2012) and has been observed previously in patients carrying C8ORF37 mu- tations (Heon et al., 2016; Katagiri et al., 2016). In C8orf37 $7^{\mathrm{del} / \mathrm{del}}$ mice at the same age, the ONL containing photoreceptor nuclei appeared to be slightly thinner (Fig. $4 A$ ), indicating a small loss of photoreceptors. Further examination of 6-month-old C8orf $37^{\mathrm{del} / \mathrm{del}}$ mice revealed that, in addition to the loss of the IS/OS line, the ONL thickness was significantly reduced (Fig. 4A), leading to decreased thickness of the entire retina compared with $C 80 r f 37^{+/ \text {del }}$ mice $\left(F_{(1,80)}=74.42, p<0.0001\right.$ for horizontal meridian; $F_{(1,80)}=128.3, p<0.0001$ for vertical meridian, two-way ANOVA with repeated measures; Fig. $4 B$ ). Therefore, retinas of C8orf $37^{\mathrm{del} / \mathrm{del}}$ mice undergo progressive photoreceptor cell loss.

Histological examination of retinal cross-sections showed that the various retinal layers of $C 80 r f 37^{\mathrm{del} / \mathrm{del}}$ mice were grossly normal at P13 and P16 (Fig. 4C). At P49, the photoreceptor OS length and ONL thickness at the midperipheral retina were reduced by $29 \%$ and $17 \%$, respectively $\left(F_{(1,64)}=18.66, p=0.0025\right.$ for OS length; $F_{(1,56)}=10.69, p=0.0137$ for ONL thickness, two-way ANOVA with repeated measures; Fig. 4C,D). At P208, further ONL thinning and OS shortening were observed in 

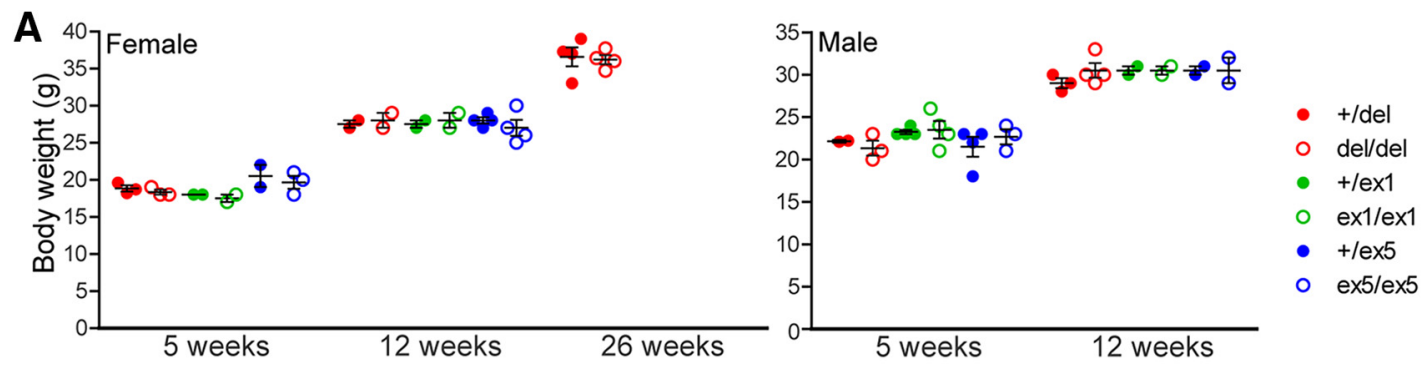

B

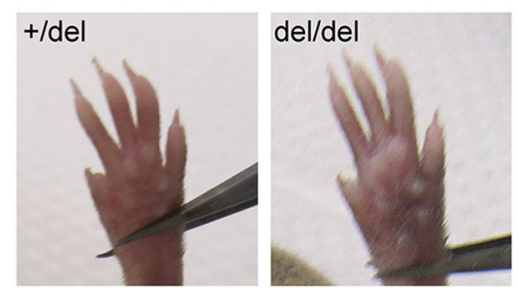

C

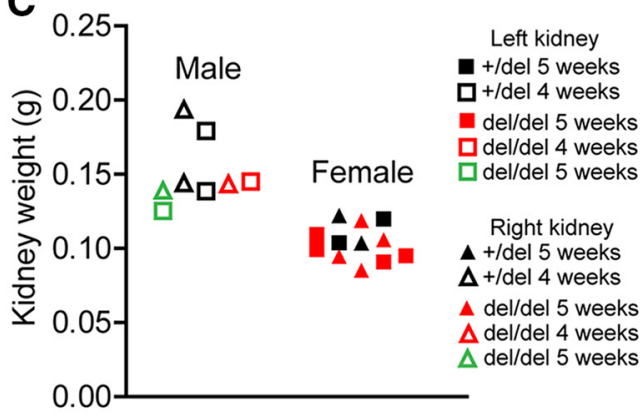

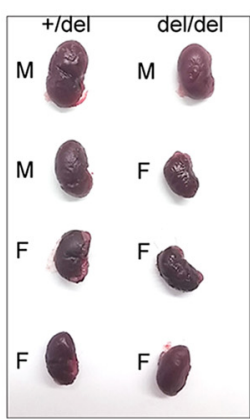

Figure 2. Normal body weight, digit number, and kidney morphology in C 8 orf37 K0 mice. $A$, Body weight of female (left) and male (right) 88 orf3 $37^{\mathrm{ex} 1 / \mathrm{ex} 1},\left(80 \mathrm{orf3} 7^{\mathrm{ex} 5 / \mathrm{ex} 5}\right.$, and $\left(8 \mathrm{orf3} 7^{\mathrm{del} / \mathrm{del}} \mathrm{mice}\right.$ is comparable to that of their heterozygous littermates up to 26 weeks of age. Data are shown as mean \pm SEM as well as individual data points. $\boldsymbol{B}$, No polydactyly was observed in $\sim 70$ C 8 orf 37 del/del mice or $\sim 50\left(80 r f 37^{+/ d e l}\right.$ mice. C, Left, Kidney weight appears to be normal in male and female $\left(80 r f 37^{\text {del/del }}\right.$ mice at $4-5$ weeks of age. Data are shown as individual data points. Right, the morphology of right kidney appears normal in male (M) and female (F) $\left(80\right.$ orf $37^{\text {del/del }}$ mice.

C8orf3 $7^{\text {del/del }}$ mice (Fig. $\left.4 C, D\right)$. At the midperipheral retina, ONL was reduced by $\sim 60 \%\left(F_{(1,80)}=157.4, p<0.0001\right.$, two-way ANOVA with repeated measures), whereas the OS was too short and distorted to be measured reliably. Together with the ERG data, SD-OCT and histological analyses demonstrated that C8orf $37^{\mathrm{del} / \mathrm{del}}$ mice exhibit a retinal degenerative phenotype similar to that seen in patients carrying mutations in the C8ORF37 gene (van Huet et al., 2013; Heon et al., 2016; Katagiri et al., 2016).

\section{Disorganization of photoreceptor OS discs in C8orf $37 \mathrm{KO}$ mice}

To examine the morphology and ultrastructure of C8orf $37^{\mathrm{del} / \mathrm{del}}$ photoreceptors, we performed SEM and TEM. SEM at P10 revealed that the developing rudimentary OS had an abnormal shape (Fig. 5A). The OS was generally swollen and also constricted at random spots. Further examination at P30 revealed that the $C 8$ orf $37^{\mathrm{del} / \mathrm{del}}$ OS was $\sim 30 \%$ wider than the $C 8$ orf $37^{+/ \mathrm{del}}$ OS $\left(t_{67}=7.78, p<0.0001\right.$, unpaired and two-tailed $t$ test; Fig. $5 B, D)$. Likely reflecting the increase in the average OS diameter, the OS density in C8orf $37^{\mathrm{del} / \mathrm{del}}$ mice was $\sim 20 \%$ less than that in C8orf $37^{+/ \text {del }}$ mice $\left(t_{67}=12, p<0.0001\right.$, unpaired and two-tailed $t$ test; Fig. $5 B, D)$. The C8orf $37^{\mathrm{del} / \mathrm{del}}$ OS also displayed a larger variation in diameter than the C8orf $37^{+/ \mathrm{del}} \mathrm{OS}\left(t_{67}=4.42, p<\right.$ 0.0001, unpaired and two-tailed $t$ test; Fig. $5 B, D)$.

TEM examination from $\mathrm{P} 13$ to $\mathrm{P} 60$ revealed massive disorganization of membrane discs inside the C8orf $37^{\mathrm{del} / \mathrm{del}}$ OS (Fig. $6 \mathrm{~A}$ and data not shown). Although discs in the C8orf $37^{+/ \text {del }}$ OS were organized in a single stack perpendicular to the long OS axis (Fig. $6 B)$, the $C 8$ orf $37^{\mathrm{del} / \mathrm{del}}$ OS contained additional disc stacks parallel to the long axis (Fig. $6 A, D, F, G$ ) and abnormal membranous whirls (Fig. 6D). The vertically aligned disc membranes appeared to overgrow from the horizontally aligned discs at random places along the entire OS (Fig. 6A,F) and no plasma membrane was observed between the vertical and horizontal disc membrane clusters (Fig. 6G), indicating that the vertical and horizontal membrane structures coexist in the same C8orf $37^{\mathrm{del} / \mathrm{del}}$ OS. The prevalence of OS with vertical disc membranes and membranous whirls varied from region to region, with an average of $\sim 50 \%$ of total OS at P25. When the OS had no vertical disc membranes or membranous whirls, the OS usually had a crooked shape with its membrane discs having uneven diameters (Fig. 6A). This observation explained the abnormal $C 80 r f 37^{\mathrm{del} / \mathrm{del}}$ OS shape that we observed by SEM (Fig. 5). Occasionally, abnormal vesicular clusters were found at the IS/OS junction of C8orf $37^{\text {del/del }}$ photoreceptors (Fig. 6E). Other subcellular structures and compartments of $C 80 r f 37^{\mathrm{del} / \mathrm{del}}$ photoreceptor cells, including the connecting cilium (Figs. $5 \mathrm{C}, 6 \mathrm{H}$ ), basal body (Fig. $6 H$ ), ciliary rootlet (Fig. $6 H$ ), and synaptic terminus (Fig. 6I), displayed no obvious ultrastructural defects.

\section{Reduction of photoreceptor OS membrane proteins in C8orf37 KO mice}

To characterize the defects in C8orf $37^{\mathrm{del} / \mathrm{del}}$ photoreceptors at the molecular level, we examined photoreceptor protein expression by semi-quantitative immunoblot analysis. At P30, the amount of OS membrane proteins, including rhodopsin, cone opsins (S/M-opsins), guanylate cyclase 1 (GC1), peripherin 2/RDS (PRPH2), cyclic nucleotide gated channel $\alpha 1$ - and $\beta 1$-subunits (CNGA1 and $\mathrm{CNGB} 1$ ), and ATP-binding cassette subfamily A member 4 (ABCA4), was reduced by $30-70 \%$ compared with control C8orf $37^{+/ \text {del }}$ littermates (unpaired and two-tailed $t$ test; Fig. $7 A-$ $C)$. The content of non-membrane proteins associated with GC1 and CNGB1 was also reduced in C8orf $37^{\text {del/del }}$ photoreceptors, including guanylate cyclase-activating protein 1 and 2 (GCAP1 and GCAP2) and glutamic acid-rich protein 2 (GARP2) (unpaired and two-tailed $t$ test; Fig. $7 A-C)$.

In contrast, three OS membrane proteins, guanylate cyclase 2 (GC2), protocadherin-21 (PCDH21), and CNGB3, were not affected by the loss of C8orf37. The expression of membraneassociated transducin $\alpha$-subunit (GNAT1), cytoplasmic protein 
A Scotopic, 5 weeks

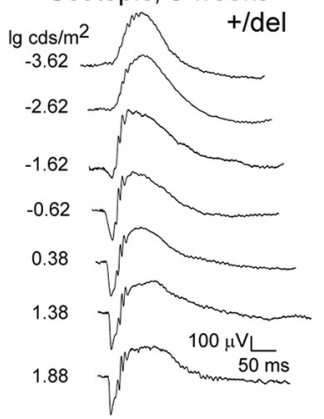

del/del

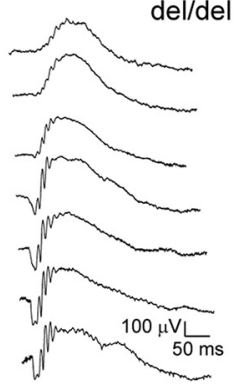

B Photopic, 5 weeks

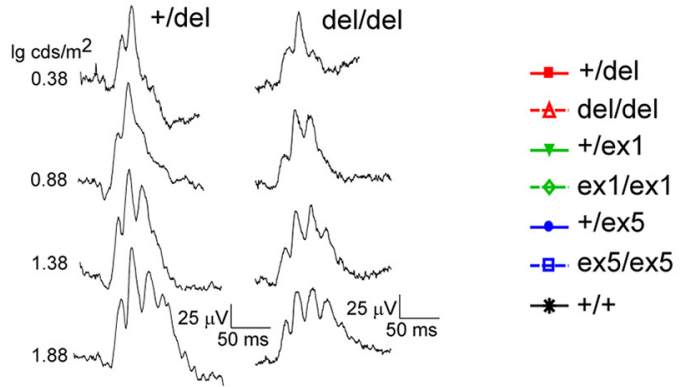

C
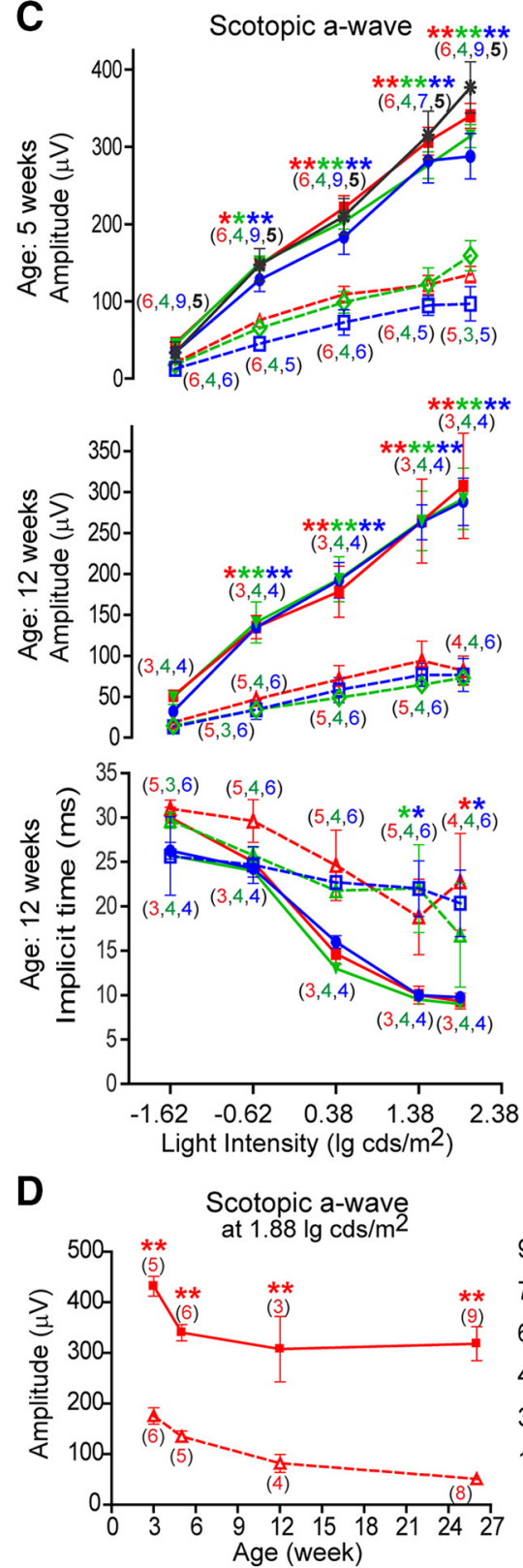
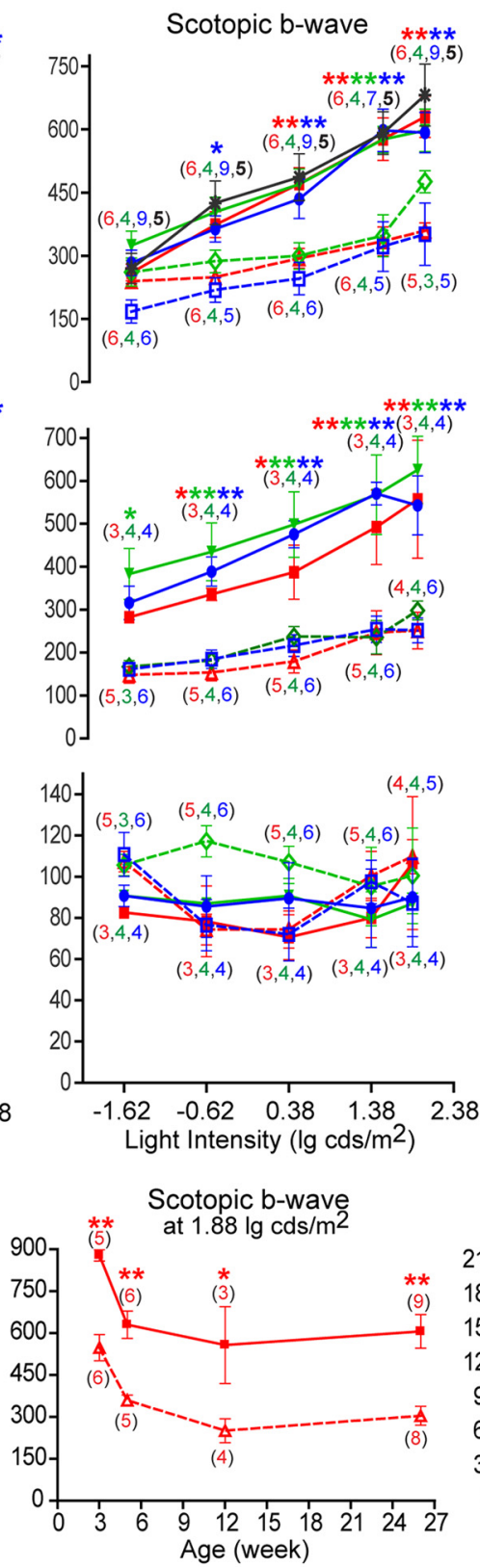

Photopic b-wave
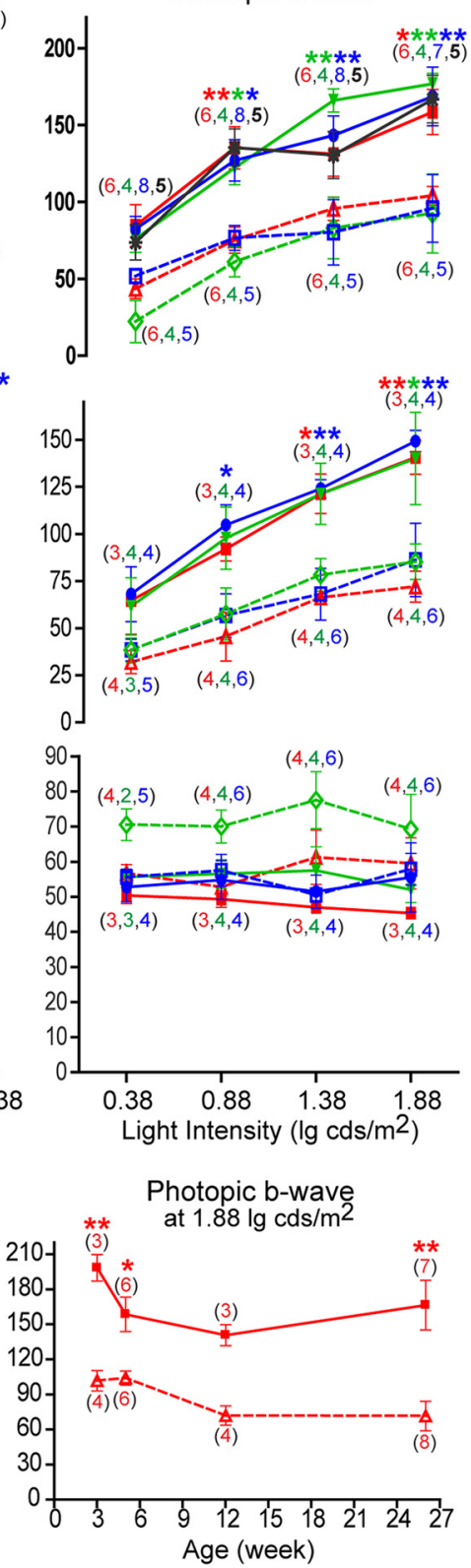

Figure 3. C8orf37 $\mathrm{KO}$ mice have reduced scotopic and photopic ERG responses. $\boldsymbol{A}$, Representative scotopic ERG responses at various light intensities from 5-week-old C8orf37 ${ }^{+/ \text {del }}$ and C8orf3 $7^{\text {del/del }}$ littermates. B, Representative photopic ERG responses at various light intensities from 5-week-old C8orf3 ${ }^{+/ \text {del }}$ and C8orf37 ${ }^{\text {del/del }}$ littermates. C, Reduced scotopic ERG a-wave

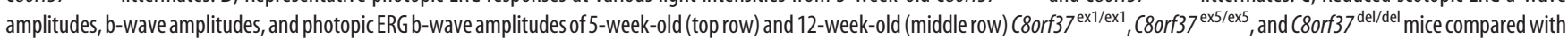
their heterozygous and wild-type littermates. Bottom row, $\left(80 \mathrm{orf3} 7^{\mathrm{ex} 1 / \mathrm{ex} 1},\left(8 \mathrm{orf3} 7^{\mathrm{ex} 5 / \mathrm{ex} 5}\right.\right.$, and $\left(80 \mathrm{orf3} 7^{\mathrm{del} / \mathrm{del}}\right.$ mice at 12 weeks of age have prolonged scotopic a-wave implicit times at the light intensities of 1.38 and $1.88 \mathrm{lg} \mathrm{cds} / \mathrm{m}^{2}$, whereas their scotopic and photopic b-wave implicit times are normal. $\boldsymbol{D}$, Changes in scotopic ERG a-wave amplitudes, b-wave amplitudes and photopic ERG b-wave amplitudes at $1.88 \mathrm{lg} \mathrm{cds} / \mathrm{m}^{2}$ in $880 \mathrm{orf3} 7^{+/ \mathrm{del}}$ and $\left(80 \mathrm{orf3} 7^{\mathrm{del} / \mathrm{del} l}\right.$ littermates from 3-26 weeks of age. Legends for each genotype are shown on top right. Data are presented as mean \pm SEM. ${ }^{*} p<0.05$ and ${ }^{* *} p<0.01$. Mutant mice were compared with their respective heterozygous littermates. Numbers in the parentheses are numbers of animals tested at each light intensity or age point. Color of the numbers and asterisks matches the color of genotypes. 
A
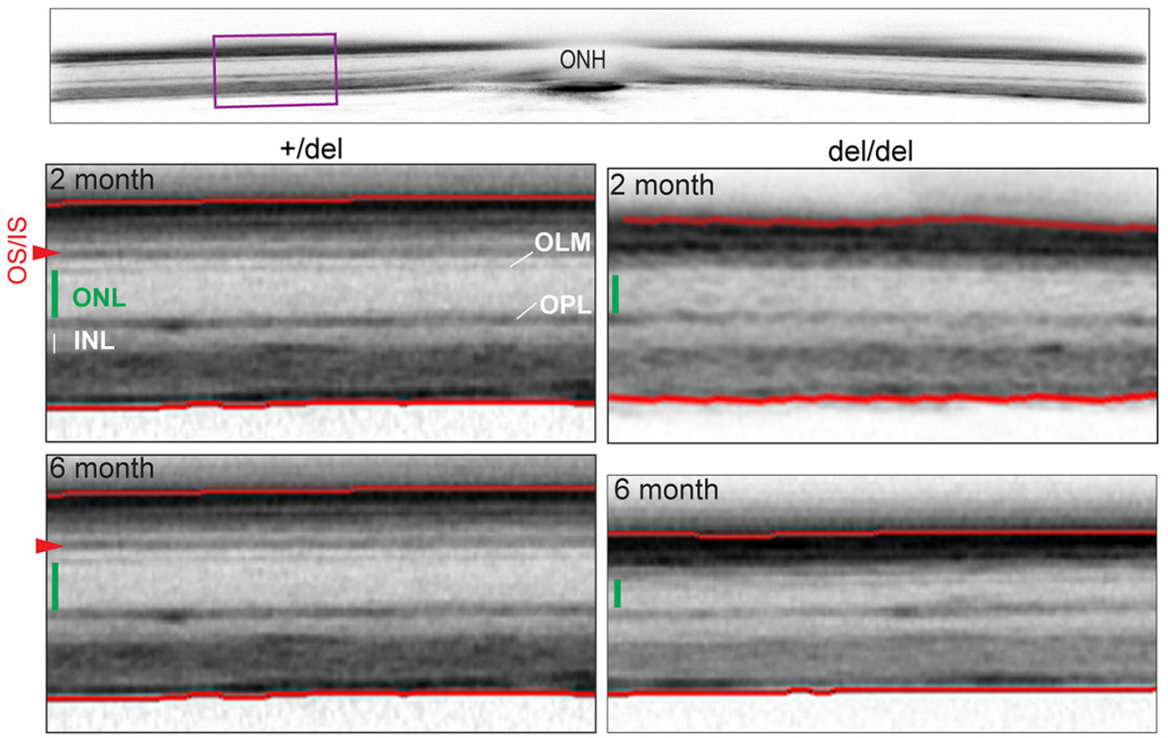

B
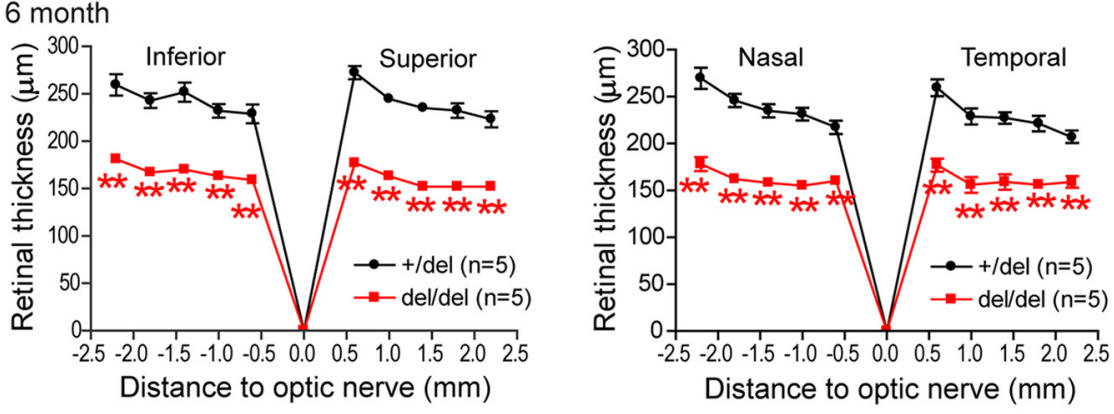

C

$\mathrm{P} 13$
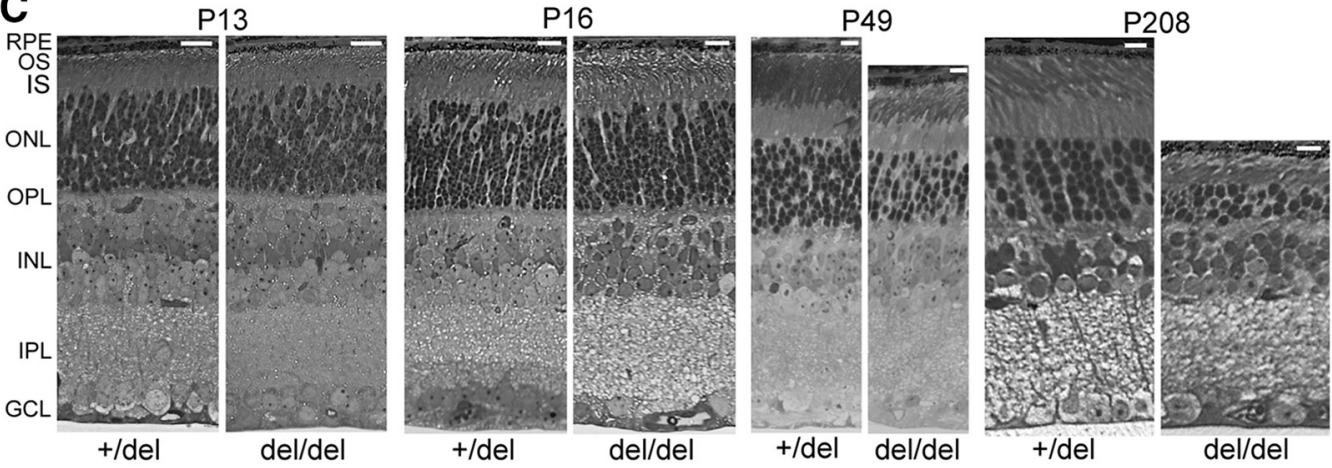

D $\quad$ P49
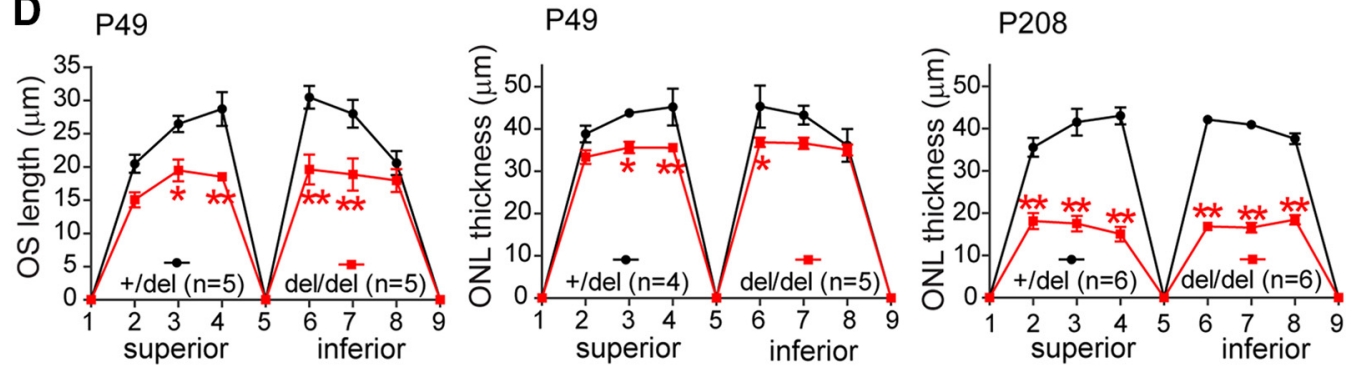

Figure 4. C $\quad 8$ orf $37^{\text {del/del }}$ mice show progressive retinal degeneration. A, Representative SD-OCT images of $C 80 r f 37^{+/ d \text { del }}$ and $\left(8\right.$ orf $37^{\text {del/del }}$ retinas at 2 and 6 months of age. The top panel is a wide-field SD-0CT image of a ( 8 orf $37^{+/ \text {del }}$ retina at 2 months of age. The center of the retinal image is the optic nerve head (ONH). The $0 \mathrm{CT}$ images of $\left(80 \mathrm{orf} 37^{+/ \mathrm{del}}\right.$ and $\left(80 \mathrm{orf} 37^{\mathrm{del} / \mathrm{del}}\right.$ retinas that are enlarged below were taken from their wide-field images at the region similar to that labeled by the magenta rectangle. Red arrows point to the $0 S$ and IS junction line. Green lines mark the $0 N \mathrm{~L}$ thickness. OPL, Outer plexiform layer; INL, inner nuclear layer; OLM, outer limiting membrane. B, Quantification of retinal thickness along the vertical (left) and horizontal (right) meridians from $\mathrm{C} 8 \mathrm{orf3}^{+/ \mathrm{del}}$ and $\mathrm{C} 8 \mathrm{orf3} 7^{\mathrm{del} / \mathrm{del}}$ retinal SD-OCT images at 6 months of age. C, Photoreceptor ONL and OS layers appear normal under light microscopy during postnatal development and become thinner with age in (8orf37 ${ }^{\text {del/del }}$ mice. Retinal sections were stained with methylene blue and azure Il at P13 and P16 and were stained with toluidine blue at P49 and P208. RPE, Retinal pigment epithelium; IPL, inner plexiform layer; GCL, ganglion cell layer. Scale bars, $10 \mu \mathrm{m}$. D, Quantification of OS length and ONL thicknesses at P49 (left and middle) and ONL thickness at P208 (right) along the vertical meridian in $\left(80 \mathrm{orf3} 7^{+/ \mathrm{del}}\right.$ and $\mathrm{C} 8 \mathrm{orf3} 7^{\mathrm{del} / \mathrm{del}}$ retinas. Data are presented as mean \pm SEM. $n$, Number of animals analyzed; ${ }^{*} p<0.05{ }^{* * *} p<0.01$. 

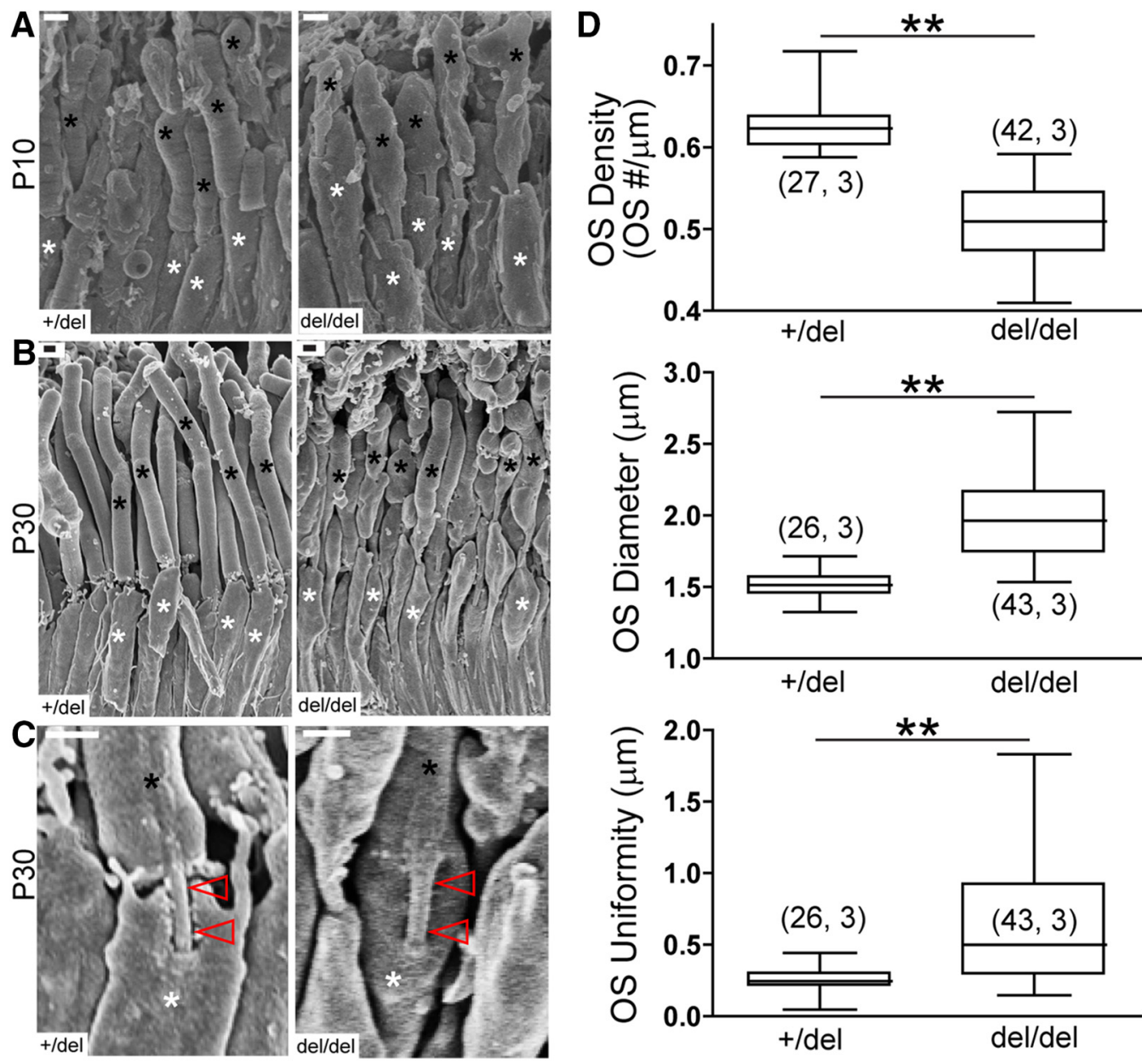

Figure 5. C $\quad 80 r f 37^{\text {del/del }}$ mice have an abnormal photoreceptor OS shape. $A$, SEM images showing an abnormal OS shape in C8orf37 del/del photoreceptors at P10 compared with littermate

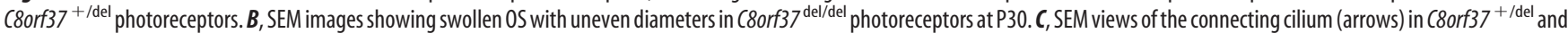
C8orf37 ${ }^{\text {del/del }}$ photoreceptors at P30. Black and white asterisks mark the 0 S and IS, respectively. Scale bars, $1 \mu \mathrm{m} . \boldsymbol{D}$, Box-and-whisker plots of the 0S density (top), diameter (middle), and uniformity (bottom) in C8orf3 $7^{+/ \mathrm{del}}$ and $\left(80 \mathrm{rf} 37^{\mathrm{del} / \mathrm{del}}\right.$ mice at P30. The upper and lower edges of the boxes represent the $25^{\text {th }}$ and $75^{\text {th }}$ percentiles, respectively, whereas the line in the boxes is the median. The top and bottom of the vertical lines mark the highest and lowest values, respectively. The numbers in the parentheses are the numbers of retinal regions or OS (before the comma) and the numbers of animals (after the comma) measured in the assay. ${ }^{* *} p<0.01$.

arrestin, and cytoskeletal protein $\beta$-tubulin also remained normal in $C 80 r f 37^{\text {del/del }}$ photoreceptors compared with $C 8$ orf $37^{+/ \text {del }}$ photoreceptors (Fig. 7A-C). Consistent with the normal structure of the photoreceptor ciliary apparatus (Figs. $6 \mathrm{H}, 5 \mathrm{C}$ ), the expression levels of the axoneme-binding protein RP1 and basal body protein $\gamma$-tubulin were normal in C8orf $37^{\text {del/del }}$ photoreceptors (Fig. 7A-C).

At P49, semiquantitative immunoblot analysis of a subset of photoreceptor proteins examined at $\mathrm{P} 30$ yielded similar results, although GC1 and CNGB1reduction had a $p$-value in the range between 0.05 and 0.1 due to their highly variable signals in the heterozygous group (unpaired and two-tailed $t$ test; Fig. 7D-F). The content of GC2 was reduced in addition to the OS membrane proteins reduced at P30. The extent of OS membrane protein reduction varied between $34 \%$ and $82 \%$, with GC1 and PRPH2 being significantly reduced from P30 (unpaired and two-tailed $t$ test; Fig. $7 G$ ). Again, the OS membrane-associated proteins, phosphodiesterase $6 \alpha / \beta$-subunits (PDE $6 \alpha / \beta)$, and GNAT1 had normal or close to normal expression levels (Fig. $7 D-F$ ).

Of the proteins with expression levels that were affected by loss of $C 8$ orf 37 , rhodopsin is the main building component of the OS membrane (Heitzmann, 1972; Robinson et al., 1972; Filipek et al., 2003) and its protein level is positively proportional to the
OS volume (Price et al., 2012). The $\sim 29 \%$ reduction in rhodopsin in P30 C8orf $37^{\text {del/del }}$ retinas (Fig. 7 B,C) would be expected to be associated with a reduction in the OS volume at this age. Indeed, we saw an $\sim 29 \%$ thinning of the OS layer in our histological analysis at P49 (Fig. 4D). However, the reduction of several OS proteins in C8orf $37^{\text {del/del }}$ retinas was $>29 \%$ at P30 and P49, particularly those proteins involved in OS disc formation: PRPH2, CNGB1, and GARP2 (Molday, 1998; Wrigley et al., 2000; Poetsch et al., 2001; Pearring et al., 2013). Taken together, these data show that the expression of multiple OS membrane proteins is reduced as a result of the C8orf $37 \mathrm{KO}$ and that the extent of this reduction is variable among different proteins.

\section{Membrane protein reduction starts before the OS disc morphogenesis in C8orf37 KO mice}

C8ORF37 was found to be expressed in the mouse retina as early as $\mathrm{P} 0$ (Fig. $8 \mathrm{~A}$ ), suggesting that C8ORF37 may play a role during mouse photoreceptor postnatal development. During this process, the formation of the connecting cilium takes place at $\mathrm{P} 3-\mathrm{P} 6$, followed by disc formation and OS extension at P8-P21 (De Robertis, 1956; Caley et al., 1972). Immunoblot analysis demonstrated that the reduction in rhodopsin expression in C8orf $37^{\mathrm{del} / \mathrm{del}}$ retinas began at $\mathrm{P} 5$, the normal onset time point for rhodopsin 

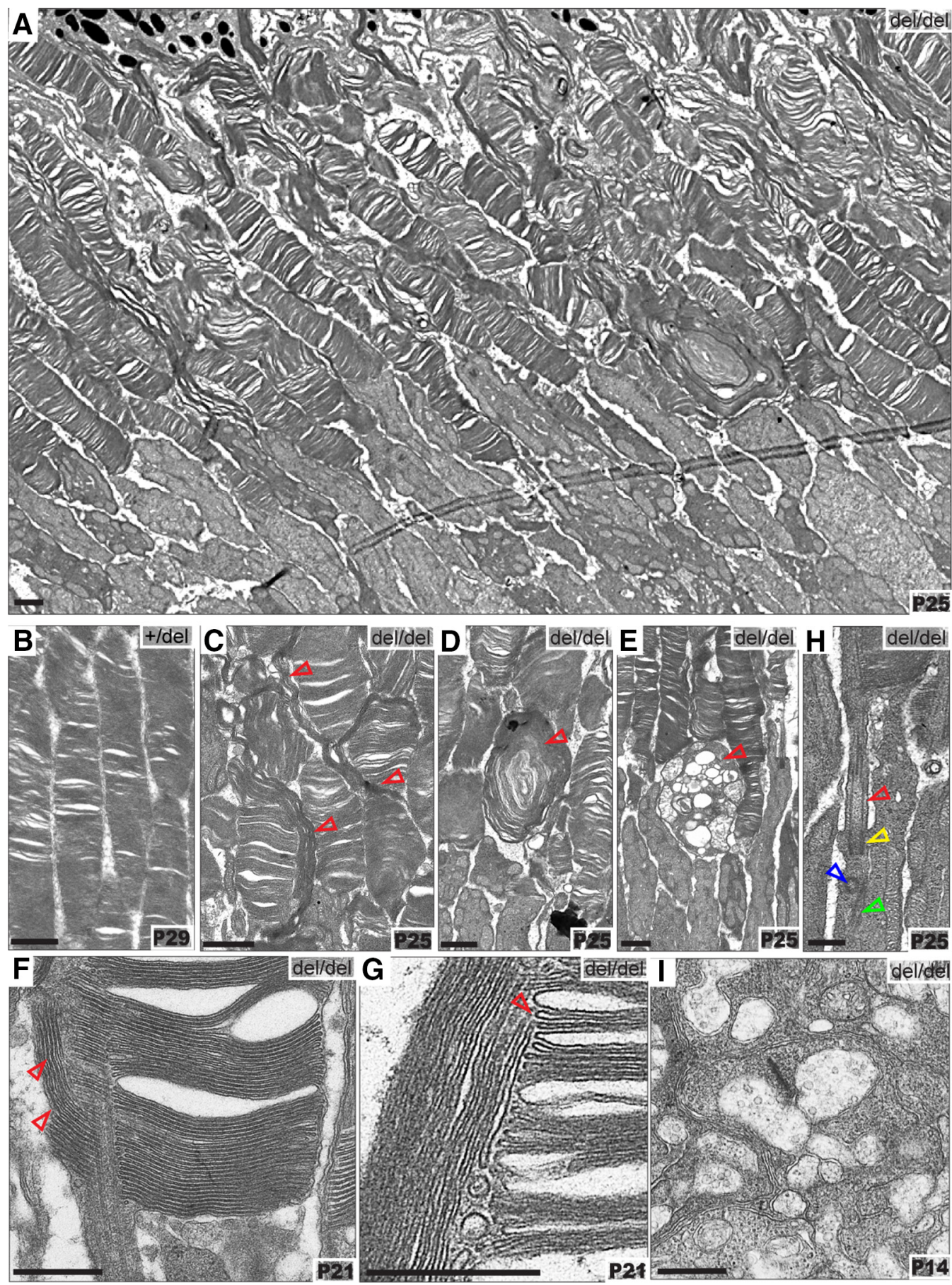

Figure 6. The (8orf3 $7^{\text {del/del }}$ OS has disorganized membrane discs. A, Massive disorganization of 05 membrane discs in C 8 orf $37^{\text {del/del }}$ mice. $\boldsymbol{B}$, Membrane discs are stacked tightly and horizontally in the control C8orf37 ${ }^{+/ \text {del }}$ OS. C, Membrane discs are wide and sometimes extend vertically (arrows) in the (8orf3 $7^{\text {del/del }}$ OS. D, Membrane whirl (arrow) is shown in the (8orf3 $7^{\mathrm{del} / \mathrm{del}}$ 0S layer. E, An abnormal multivesicular body-like structure (arrow) is occasionally present between the IS and OS layers in the 8 orf $37^{\text {del/del }}$ retina. $\boldsymbol{F}$, Vertical membrane discs grow from the edge of horizontal membrane discs (arrows) in the C8orf37 $7^{\text {del/del }}$ OS. G, No plasma membrane is present between the horizontal and vertical membrane discs (arrow) in the (8orf37 ${ }^{\text {del/del }} 0$ 0S. $\boldsymbol{H}$, (8orf3 $7^{\text {del/del }}$ photoreceptors have a normal appearance of their connecting cilium (red arrow), basal body (yellow arrow), daughter centriole (blue arrow), and ciliary rootlet (green arrow). $\boldsymbol{I}$, (8orf37 del/del $\mathrm{rod}$ photoreceptors have a normal appearance of their synaptic terminus. Age of the photoreceptors is labeled at the bottom right corner of each image. Scale bars: $\boldsymbol{A}-\boldsymbol{E}, 1 \mu \mathrm{m} ; \boldsymbol{F}-\boldsymbol{I}, 0.5 \mu \mathrm{m}$.

expression $\left(F_{(1,14)}=106.6, p<0.001\right.$, two-way ANOVA, compared with $\gamma$-tubulin expression in $C 80 r f 37^{\text {del } / \text { del }}$ retinas; Fig. $8 A, C)$. GC1, PRPH2, and S/M-opsins were expressed at much lower levels than rhodopsin during development. The onset of $\mathrm{GC} 1$ and $\mathrm{S} / \mathrm{M}$-opsin reduction in C8orf $37^{\mathrm{del} / \mathrm{del}}$ retinas was at $\mathrm{P} 12$ $\left(F_{(1,16)}=42.27, p<0.0001\right.$, two-way ANOVA) and P16 (not significant, two-way ANOVA; but $t_{7}=2.797, p=0.0266$ at P16, unpaired and two-tailed $t$ test), respectively, during the active OS extension period, wheras PRPH2 reduction occurred later than P16 (Fig. 8B,C). Therefore, the reduction in rhodopsin expression in $C 8$ orf $37^{\mathrm{del} / \mathrm{del}}$ retinas begins the earliest and before the disc formation. This observation suggests that the reduction in rhodopsin content found in C8orf $37^{\mathrm{del} / \mathrm{del}}$ retinas at later time points (e.g., P30 in Fig. 7) is likely to be a cause of the observed OS shortening rather than its consequence.

To investigate whether the reduction of OS membrane pro- 

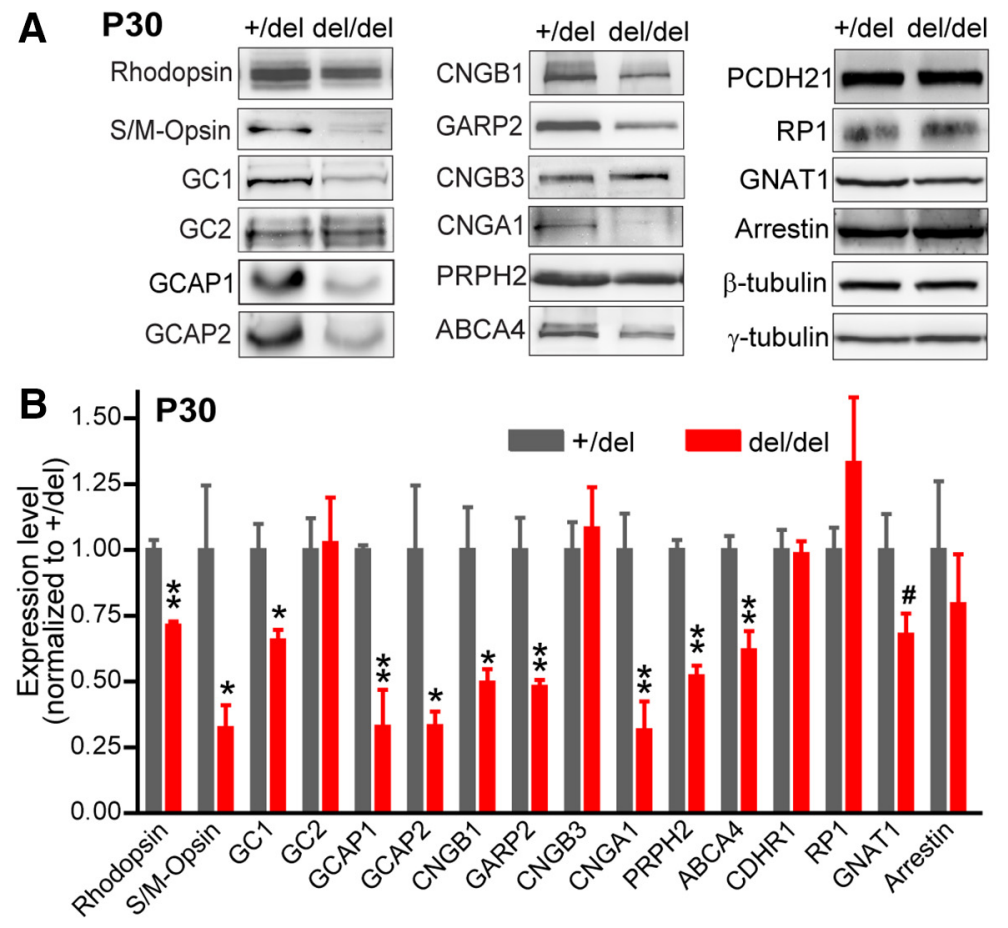

C

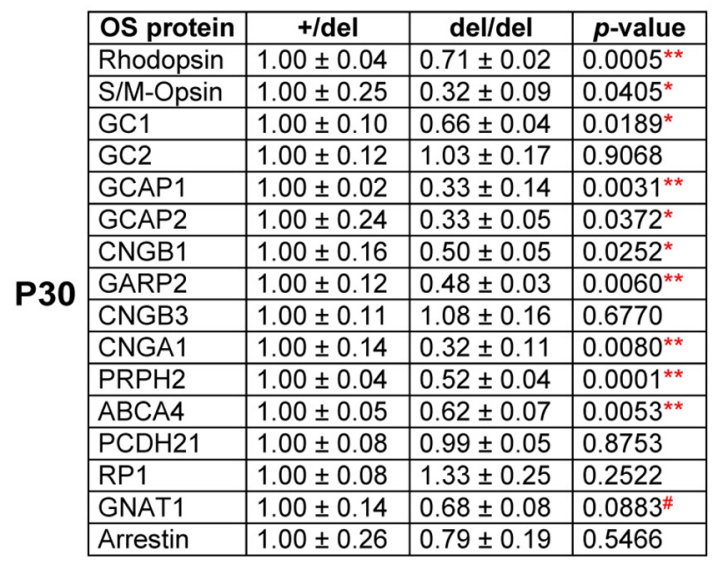
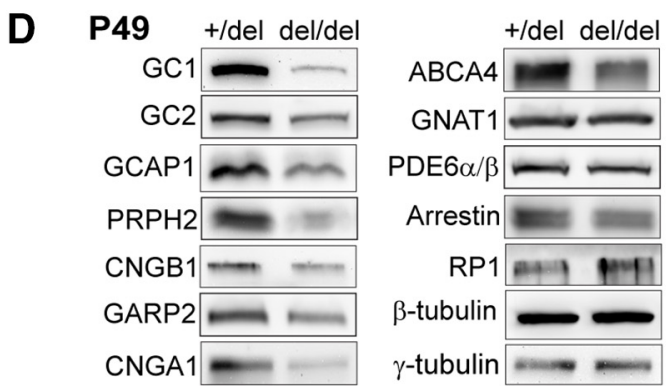

F

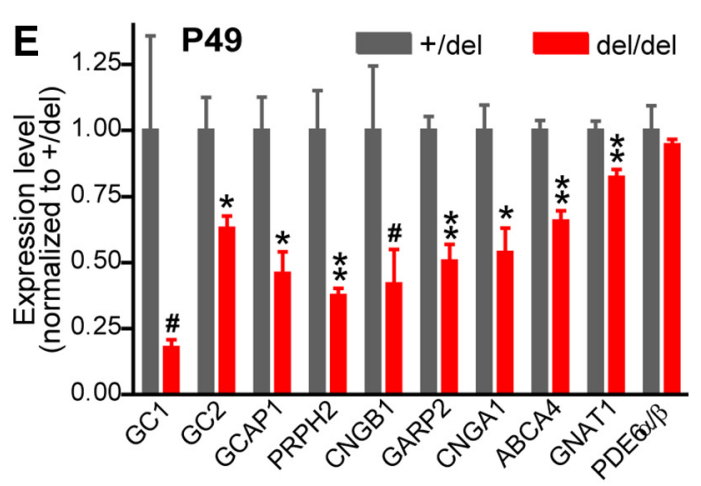

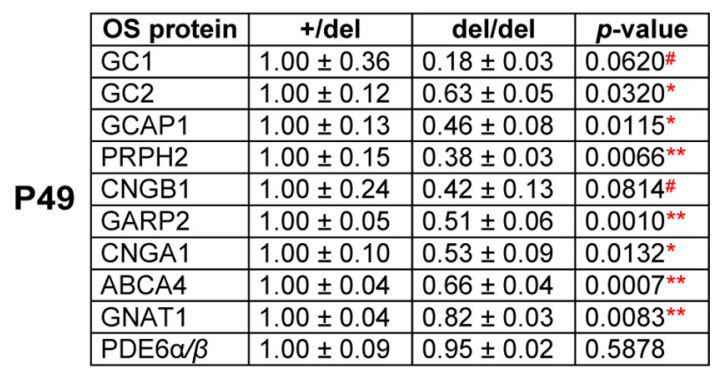

G

\begin{tabular}{|l|l|l|l|l|}
\cline { 2 - 5 } & OS protein & P30 del/del & P49 del/del & $\boldsymbol{p}$-value \\
\cline { 2 - 5 } & GC1 & $0.66 \pm 0.04$ & $0.18 \pm 0.03$ & $0.0001^{* *}$ \\
\cline { 2 - 5 } GC2 & $1.03 \pm 0.17$ & $0.63 \pm 0.05$ & $0.0695^{\#}$ \\
\cline { 2 - 5 } & GRPH2 & $0.52 \pm 0.04$ & $0.38 \pm 0.03$ & $0.0260^{*}$ \\
\hline
\end{tabular}

Figure 7. Many $0 S$ membrane proteins and their associated proteins are reduced in $C 80 r f 37^{\text {del/del }}$ retinas. $A, D$, Representative immunoblots of proteins expressed in $C 80 r f 37^{+/ d \text { del }}$ and

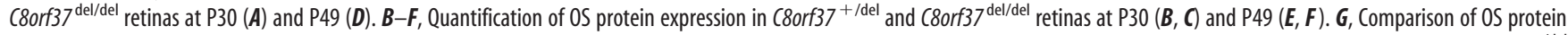
expression between P30 and P49. The expression of each protein was first normalized by its corresponding loading control, $\gamma$-tubulin, and then normalized by the mean value of the $\left(80\right.$ orf $37^{+/ \text {del }}$ group. Data are presented as mean \pm SEM in both the bar chart $(\boldsymbol{B}, \boldsymbol{E})$ and the table $(\boldsymbol{C}, \boldsymbol{F}, \boldsymbol{G})$. Four mice were analyzed for each genotype. $\# p<0.1 ;{ }^{*} p<0.05 ;{ }^{* *} p<0.01$.

teins was caused by a lower rate of mRNA transcription, we performed qRT-PCR. After normalization by the mRNA level of GAPDH, the mRNA levels of rhodopsin, M-opsin, S-opsin, GC1, and PRPH2 were similar between C8orf37 ${ }^{+/ \mathrm{del}}$ and C8orf $37^{\mathrm{del} / \mathrm{del}}$ retinas at P5 (Fig. $8 D$ ). The mRNA levels of GC1 and PRPH2 remained normal in $\operatorname{Corf} 37^{\mathrm{del} / \mathrm{del}}$ retinas at $\mathrm{P} 27$, whereas the mRNA levels of rhodopsin and S-opsin started to decrease at P15 $\left(F_{(1,6)}=13.86, p=0.0098\right.$, two-way ANOVA with repeated measures $)$ and P27 $\left(F_{(1,24)}=25.38, p=0.001\right.$, two-way ANOVA with repeated measures), respectively (Fig. $8 D$ ). At $\mathrm{P} 27$, the reduction of rhodopsin and S-opsin was $42 \%$ and 32\%, respectively (Fig. $8 D$ ). Because the reduction of rhodopsin, GC1, and S/M-opsin proteins occurred at P5, P12, and P16, respectively, when their mRNA levels were normal, we concluded that the OS membrane protein reduction in $C 80 r f 37^{\mathrm{del} / \mathrm{del}}$ retinas was not due to abnormal mRNA transcription and some of these protein reductions might somehow lead to mRNA reduction.
C8ORF37 is localized throughout the photoreceptors but not their OS

Immunoblot analysis showed that C8ORF37 protein is expressed in multiple mouse tissues, including the brain, kidney, lung, spleen, heart, trachea, and testis (data not shown). In mouse photoreceptors, C8ORF37 was reported previously to be enriched at the basal body and ciliary rootlet by immunofluorescence using a commercial antibody (Estrada-Cuzcano et al., 2012). Using the same commercial antibody as well as our four different custom-made C8ORF37 antibodies, we could not detect a specific signal for C8ORF37 in C8orf $37^{+/ \text {del }}$ photoreceptors, because C8orf $37^{\text {del/del }}$ photoreceptors exhibited a similar immunoreactivity pattern, presumably reflecting antibody nonspecific cross-reactivity (data not shown). We thus investigated the GFP-tagged and FLAG-tagged C8ORF37 distribution in photoreceptors. To reduce the potential problem of overexpression, we transfected the tagged C8ORF37 plasmids individually into C8orf $37^{\mathrm{del} / \mathrm{del}}$ photoreceptors by in vivo electro- 
A

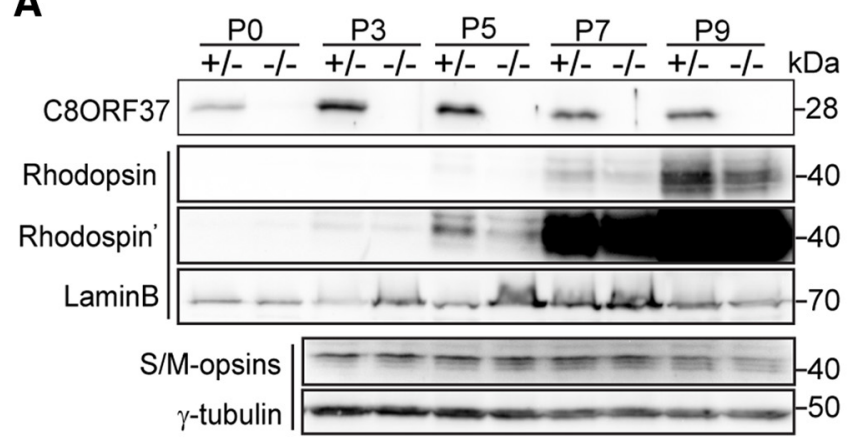

B

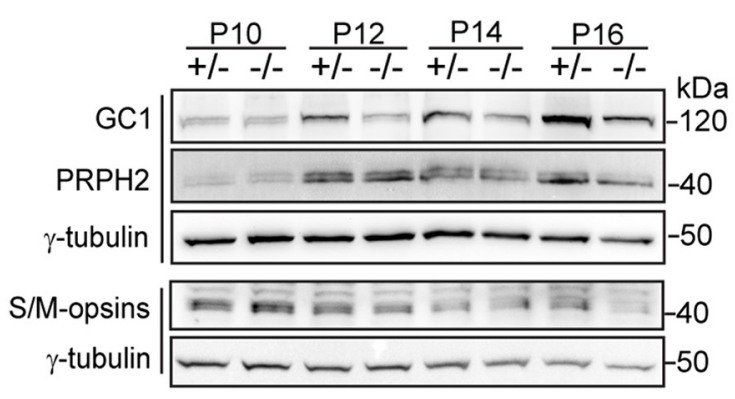

D

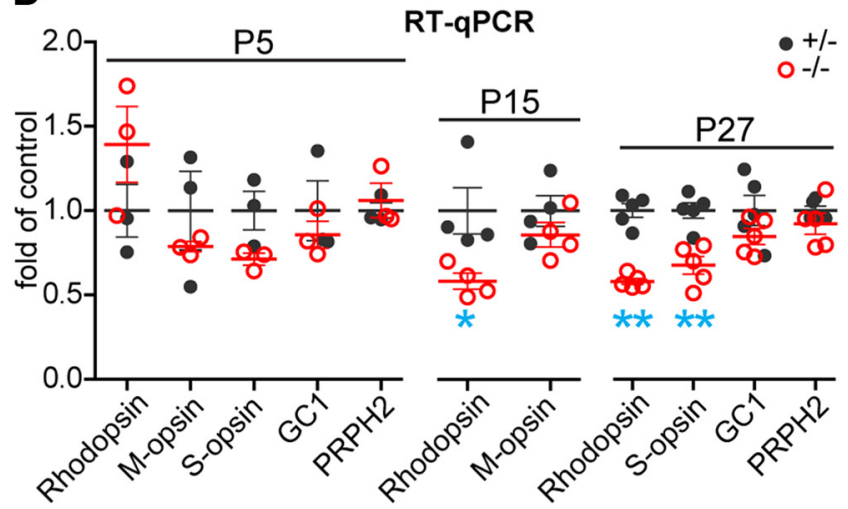

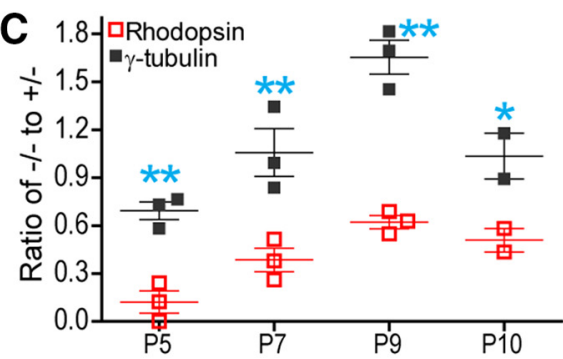
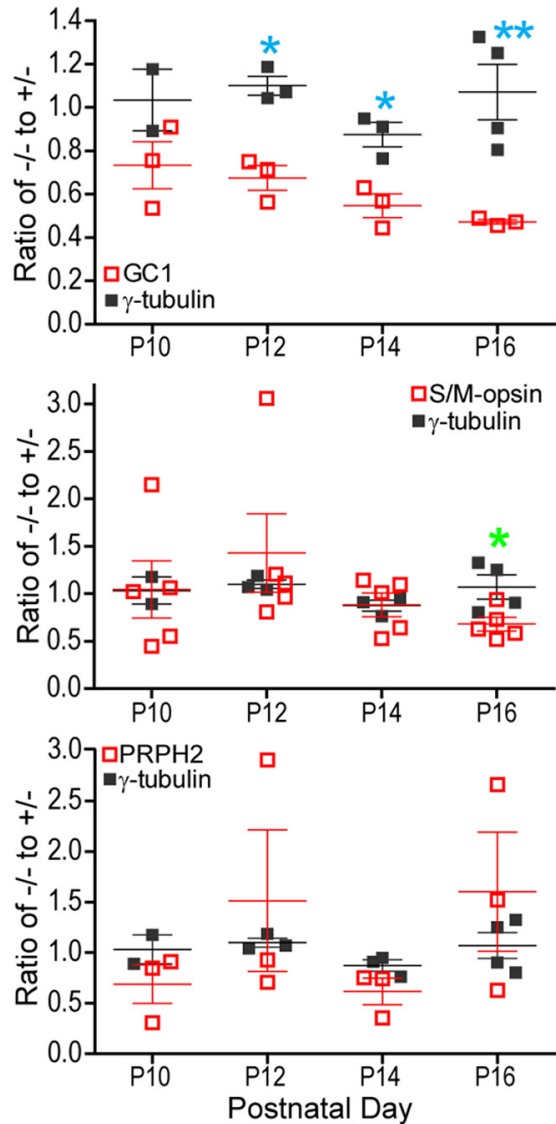

Figure 8. Onset of OS membrane protein reduction during C8orf3 $7^{\text {del/del }}$ OS morphogenesis. $A$, Expression of C80RF37, rhodopsin and S/M-opsin proteins in C8orf37 ${ }^{+/ \text {del }}(+/-)$ and C $80 r f 37^{\text {del/del }}(-1-)$ retinas before OS elongation. The blots labeled with rhodopsin and rhodopsin' are the same blot, but the signal intensity on the rhodopsin' blot was significantly enhanced to show the rhodopsin signals at P5. Lamin B and $\gamma$-tubulin are loading controls. Immunoblots labeled by the same vertical bars are from the same blots. $\boldsymbol{B}$, Expression of GC1, PRPH2, and S/M-opsin proteins in $\left(80 r f 37^{+/ \text {del }}\right.$ and C8orf3 $7^{\text {del/del }}$ retinas during OS elongation. $\gamma$-tubulin is a loading control. C, Ratios of rhodopsin, GC1, S/M-opsin, and PRPH2 protein expression in C 8 orf3 $7^{\text {del/del }}$ retinas to those in $80 \mathrm{orf3} 7^{+/ \text {del }}$ retinas during postnatal development. The ratios of these proteins (red) are compared with the ratios of control protein $\gamma$-tubulin (black) from the same animals. Individual data points are shown as ratios calculated from $\left(80 r f 37^{\text {del/del }}\right.$ and $\left(80 r f 37^{+/ \text {del }}\right.$ retinas at the same developmental time points on the same immunoblots. Means and SEM are also shown. $D, q R T-P C R$ results showing the ratios of rhodopsin, $\mathrm{M}$-opsin, S-opsin, GC1, and PRPH2 mRNA levels (normalized by GAPDH mRNA levels) in C 80 rf $37^{\text {del/del }}$ retinas to those in $C 8$ orf37 ${ }^{+/ \text {del }}$ retinas at P5, P15, and P27. ${ }^{*} p<0.05 ;{ }^{* *} p<0.01$; cyan asterisks, $p$-values from Bonferroni post tests between C 8 orf3 $7^{\text {del/del }}$ and 88 orf $37^{+/ \text {del }}$ groups; green asterisk, $p$-value from Student's $t$ test between $C 8$ orf37 ${ }^{\text {del/del }}$ and $\left(80 r f 37^{+/ \text {del }}\right.$ groups at a single time point (i.e., P16).

poration at P0. At P21, both GFP-C8ORF37 and FLAG-C8ORF37 proteins were evenly distributed throughout the photoreceptor cell volume except for the rod and cone OS, which was marked by rhodopsin/CNGB1 and S/M-opsins, respectively (Fig. 9A,B). In the IS, immunostaining of the ciliary rootlet using a rootletin antibody showed that GFP-C8ORF37 was present at the basal body region on the top of the ciliary rootlet (Fig. 9C). However, no GFP-C8ORF37 enrichment was observed at the basal body or ciliary rootlet. Because transfected recombinant proteins generally show similar subcellular distributions to their endogenous counterparts as revealed by immunofluorescence (Stadler et al., 2013) and both GFP-C8ORF37 and FLAG-C8ORF37 displayed a similar distribution pattern, our result suggests that C8ORF37 is broadly distributed in photoreceptors and is only restricted from the OS. Consistently, in serum-starved IMCD3 cells, we observed transfected GFP-C8ORF37 to be evenly distributed in the cytoplasm, but not in the primary cilium (Fig. 9E), an analog of the photoreceptor OS.

To provide evidence for endogenous C8ORF37 localization in the photoreceptor, we followed protein distribution in serial tangential sections through the photoreceptor layer of a flatmounted rat retina (Sokolov et al., 2002). The endogenous C8ORF37 expression profile in the serial sections, determined by immunoblot analysis, was comparable to that of the photoreceptor marker PDC, but not the expression profile of the photoreceptor OS marker PRPH2 (Fig. 9D). Together, these results support the notion that C8ORF37 is localized to the photorecep- 

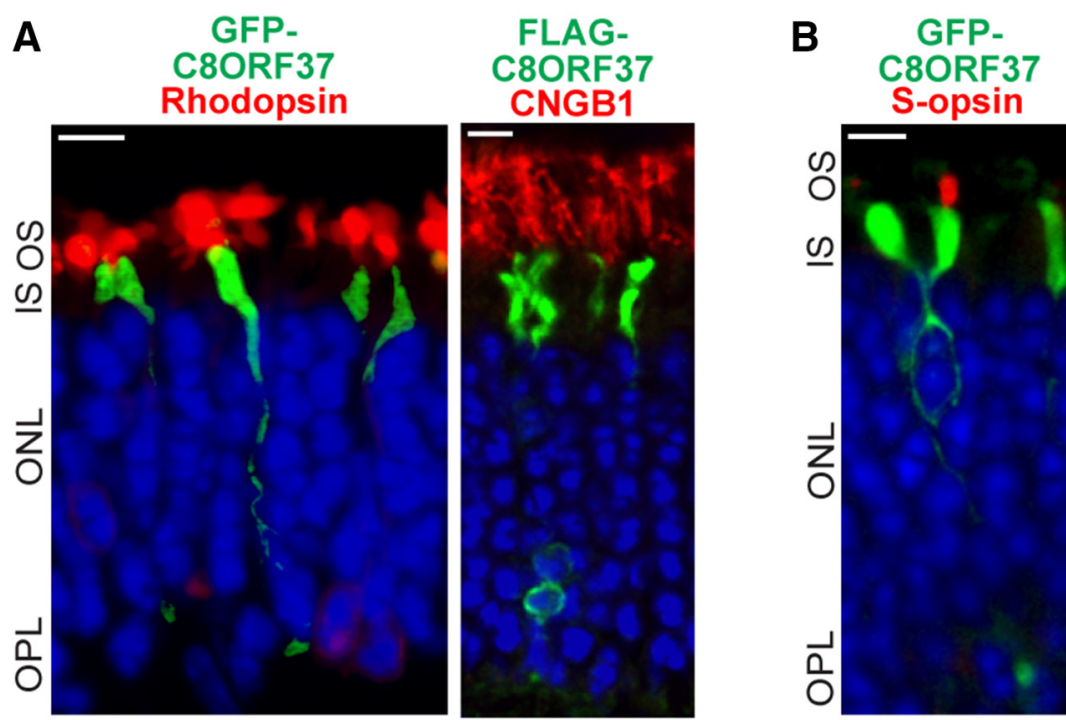

FLAG-
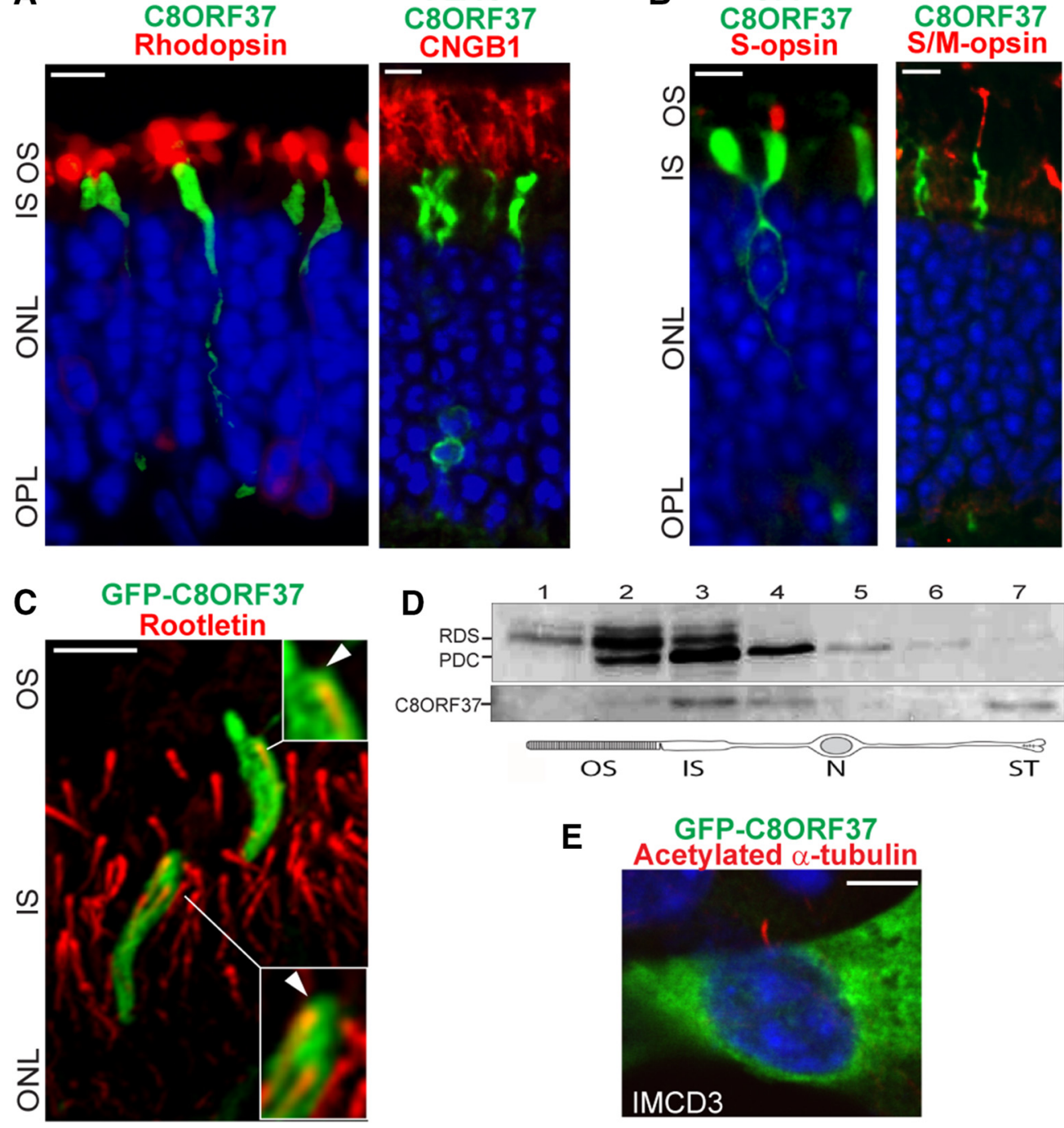

Figure 9. C80RF37 is localized to the cell body but not the OS in photoreceptors. $\boldsymbol{A}, \boldsymbol{B}$, Transfected GFP-C80RF37 (green) or FLAG-C80RF37 ( $g r e e n)$ is localized to rod ( $\boldsymbol{A})$ and cone $(\boldsymbol{B})$ photoreceptor cell bodies in the IS, ONL, and outer plexiform layer (OPL) of (8orf37 ${ }^{\text {del/del }}$ retinas at P21. Rhodopsin and CNGB1 (red) are markers for the rod OS and S/M-opsins (red) are markers for the cone 0S. Hoechst 33342 dye (blue) labels the photoreceptor nuclei. C, GFP-C80RF37 is evenly distributed in the IS and is marked by rootletin (red). Insets, GFP-C80RF37 is present in the region above the apical tip of the rootletin signal where the basal body is located (arrows). D, Distribution of (8ORF37 in seven $20 \mu \mathrm{m}$ serial tangential sections throughout the photoreceptor layer of a flat-mounted rat retina. Relative contents of (80RF37, PDC (a photoreceptor marker), and PRPH2 (a photoreceptor OS marker) were analyzed by immunoblotting with corresponding antibodies. A diagram of a photoreceptor beneath the immunoblotting panels depicts the subcellular origin of each section. Note that portions of OS and IS naturally overlap in sections 2 and 3 . N, Nucleus; ST, synaptic terminus. $\boldsymbol{E}$, Transfected GFP-C8ORF37 (green) is evenly distributed in the cytoplasm but not the primary cilium, labeled by acetylated $\alpha$-tubulin (red), in a serum-starved IMCD3 cell. Blue indicates nuclear staining from Hoechst 33342 . Scale bars, $5 \mu \mathrm{m}$.

tor cell body including the basal body, IS, and synaptic terminus, but not the OS.

\section{Normal targeting of most OS membrane proteins in C8orf37 KO photoreceptors}

The data presented so far indicate that the major phenotypic features of the C8orf $37 \mathrm{KO}$ are confined to the photoreceptor OS, whereas C8ORF37 is localized outside this cellular compartment. This suggests that C8ORF37 participates in a cellular process that relates to OS morphogenesis but takes place in the photoreceptor cell body, where OS proteins are synthesized, sorted, and transported. Therefore, we investigated whether loss of C8orf37 is associated with any defects in the cellular localization of OS membrane proteins.

Immunostaining of $C 8$ or $f 37^{\mathrm{del} / \mathrm{del}}$ retinas at $\mathrm{P} 21$ showed that rhodopsin, CNGA1, PRPH2, CNGB1, and GC1 were normally localized to the OS (Fig. 10A-E). The same result was obtained for OS membrane proteins prominin- 1 and PCDH21 and the connecting cilium cytoskeletal protein acetylated $\alpha$-tubulin (Fig. 10F$H$ ). Therefore, C8ORF37 is not involved, or at least is not critical, for OS targeting of these membrane and cytoskeletal proteins. Because PRPH2, GC1, prominin-1, PCDH21, and acetylated $\alpha$-tubulin are expressed in both rods and cones (Arikawa et al., 1992; Yang et al., 1999; Rattner et al., 2001; Zacchigna et al., 2009), the lack of these proteins' mislocalization in any C8orf $37^{\text {del/del }}$ photoreceptor cells indicates that C8ORF37 is dispensable for OS targeting of these proteins in both rods and cones.

The only proteins with intracellular localization that was affected in the C8orf3 $7^{\mathrm{del} / \mathrm{del}}$ retinas were S/M-opsins. C8orf $37^{\mathrm{del} / \mathrm{del}}$ retinas consistently displayed a significant number of cones with S/M-opsins partially mislocalized to the cell body and synaptic terminus (Fig. 10I,J). Double staining with peanut agglutinin 

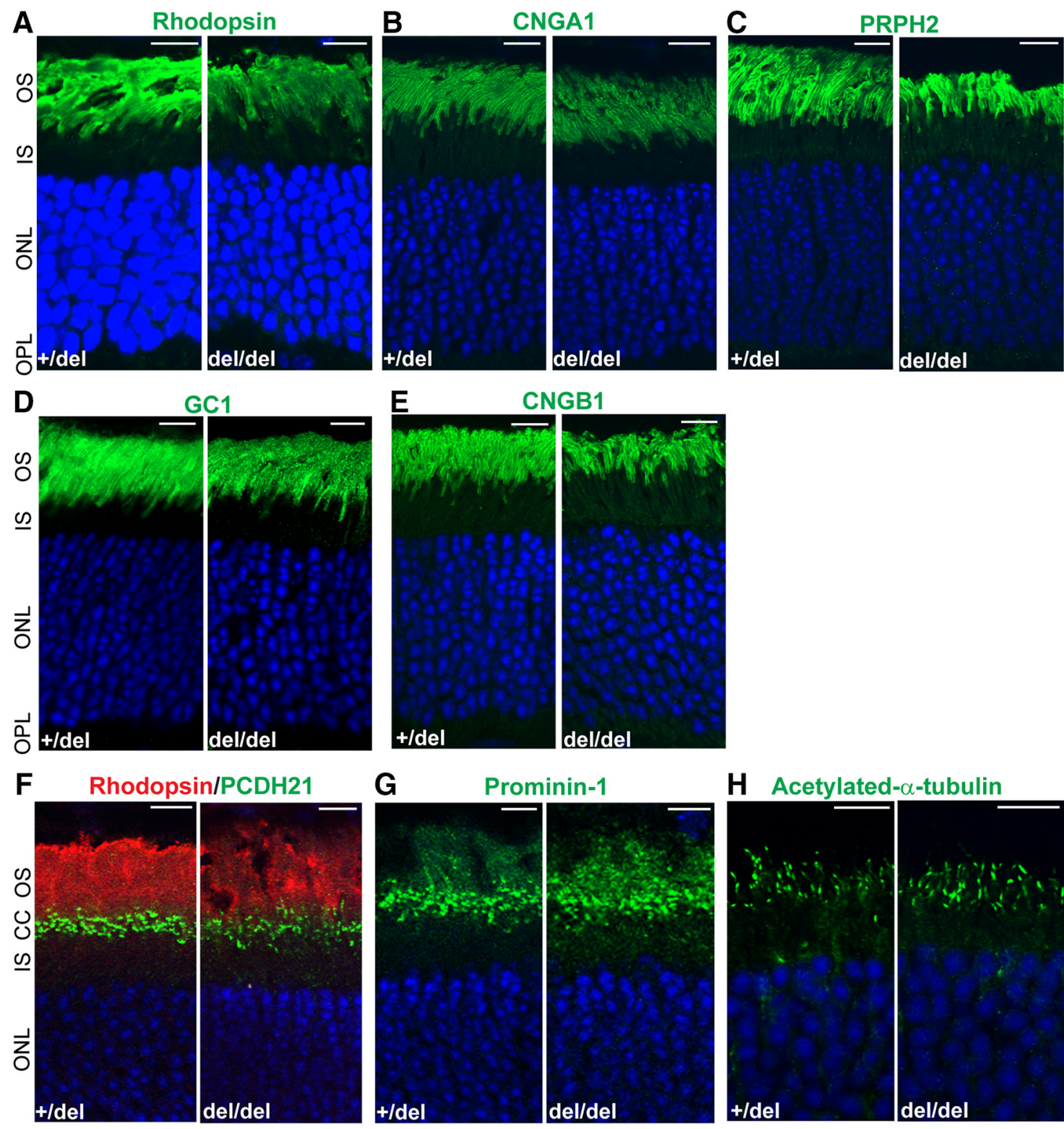

G Prominin-1

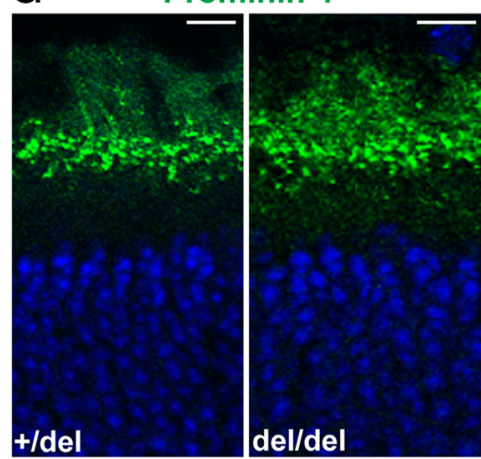

H Acetylated- $\alpha$-tubulin

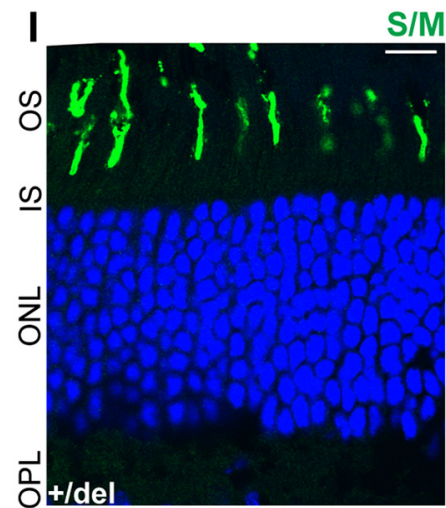

S/M-opsin
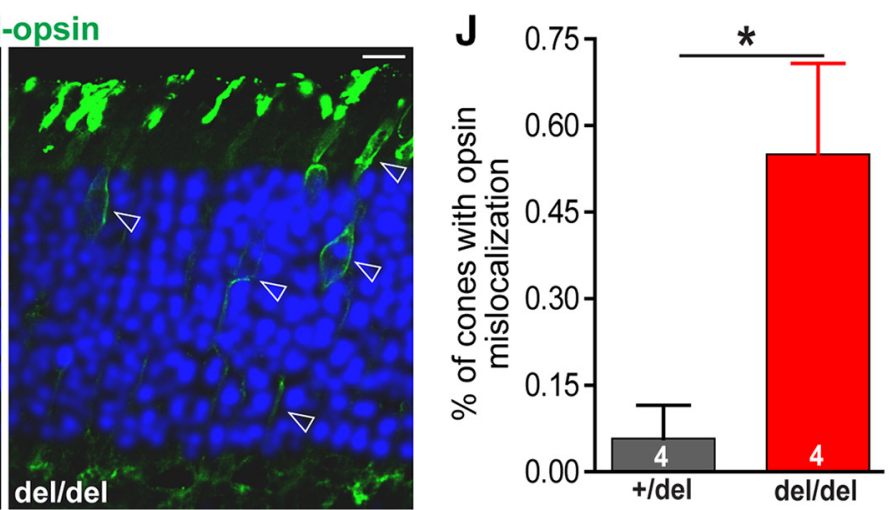

Figure 10. OS membrane proteins except $\mathrm{S} / \mathrm{M}$-opsins are distributed normally in C8orf37 ${ }^{\text {del/del }}$ photoreceptors. $\boldsymbol{A}-\boldsymbol{E}$, Immunostaining demonstrated that rhodopsin $(\boldsymbol{A})$, CNGA1 ( $\left.\boldsymbol{B}\right)$, PRPH2 ( $\boldsymbol{C}$, GC1 (D), CNGB1 (E), PCDH21 $(\boldsymbol{F})$, prominin-1 $(\boldsymbol{G})$, and acetylated $\alpha$-tubulin $(\boldsymbol{H})$ are localized normally to the 0 S or the base of 0 S in $C 80 \mathrm{rf3} 7^{\text {del/del }}$ retinas at P21. The red signal in $\boldsymbol{F}$ is from rhodopsin antibody staining. I, Immunostaining revealed partial mislocalization of S/M-opsins (arrows) in some C8orf37 ${ }^{\text {del/del }}$ cones at P21. $\boldsymbol{J}$, Quantification of cones with mislocalized S/M-opsins in the retinas of P21 $\left(80 \mathrm{orf} 37^{+/ \mathrm{del}}\right.$ and C $80 \mathrm{rf3} 7^{\mathrm{del} / \mathrm{del}}$ littermates. Data are presented as mean \pm SEM. Numbers at the bottom of bars are numbers of mice analyzed. ${ }^{*} p<0.05$. Blue signal is from Hoechst 33342 labeling the photoreceptor nucleus. CC, Connecting cilium; OPL, outer plexiform layer. Scale bars, $10 \mu \mathrm{m}$. 
confirmed that the cells with S/M-opsin mislocalization were cone photoreceptors (data not shown). Using the number of the $\mathrm{S} / \mathrm{M}$-opsin-stained OS as the total number of cones in the retina, $\mathrm{S} / \mathrm{M}$-opsins were mislocalized in $\sim 55 \%$ of $\mathrm{C} 8 \mathrm{orf} 37^{\mathrm{del} / \mathrm{del}}$ cones compared with only $\sim 6 \%$ of $C 8$ orf $37^{+/ \mathrm{del}}$ cones $\left(t_{6}=2.940, p=\right.$ 0.0259 , unpaired and two-tailed $t$ test). Although the mislocalization of cone opsins could be secondary to retinal degeneration, it may suggest that C8ORF37 participates in either cone opsin processing in the biosynthetic membranes or transport of cone opsin to the OS and that C8ORF37 may have a different functional mechanism for assisting the processing of opsins in cones than other OS membrane proteins in rods.

\section{Discussion}

C8ORF37 is a protein of unknown function, despite that mutations in C8ORF37 are associated with an array of visual disorders. The central result obtained in this study is that C8ORF37 KO in mice results in a major defect in the structural organization of photoreceptor OS discs, ultimately leading to photoreceptor cell death. Although this photoreceptor ultrastructural phenotype has been reported in several other mutant mouse models in which the mutant proteins are either photoreceptor OS or connecting cilium proteins (Hawkins et al., 1985; Sanyal et al., 1986; Rattner et al., 2001; Liu et al., 2003; Zhao et al., 2003; Yang et al., 2008; Zhang et al., 2009), C8ORF37 is excluded from the photoreceptor OS and instead is distributed throughout the rest of the cell. The reduction of OS membrane proteins in the absence of C8ORF37 documented in our study suggests that C8ORF37 plays a role in the homeostasis of these proteins while these proteins are synthesized and processed inside the photoreceptor cell body before reaching the OS.

Our finding that C8orf37 $\mathrm{KO}$ mice have both rod and cone phenotypes is consistent with clinical findings in patients with $\mathrm{RP}$ or CRD. Among the 22 reported C8ORF37-deficient patients (Estrada-Cuzcano et al., 2012; van Huet et al., 2013; Jinda et al., 2014; Lazar et al., 2014; Ravesh et al., 2015; Heon et al., 2016; Katagiri et al., 2016; Khan et al., 2016; Rahner et al., 2016), eight were diagnosed as having CRD (Estrada-Cuzcano et al., 2012; van Huet et al., 2013; Lazar et al., 2014; Rahner et al., 2016), five as having RP with early maculopathy (Estrada-Cuzcano et al., 2012; van Huet et al., 2013; Jinda et al., 2014), and two as having either CRD or RP with early maculopathy (Katagiri et al., 2016). The macula is the central retina where cones are highly concentrated in humans. The early maculopathy in C8ORF37-deficient patients may indicate early onset dysfunction of cones. Therefore, the majority of C8ORF37-deficient patients showed early symptoms of both rod and cone degeneration. In addition, in C8orf37 KO mice, many of the decreased OS membrane proteins are encoded by known causative genes for inherited retinal degeneration, such as RHO, PRPH2, CNGB1, GC1, and ABCA4, suggesting that the retinal degenerative mechanisms are, to some extent, shared among patients carrying mutations in C8ORF37 and other retinal degeneration genes.

Conversely, the reason for absence of non-ocular phenotypes in C8orf37 KO mice is unclear. In humans, C8ORF37 is a rare causative gene for BBS (Heon et al., 2016). Only two C8ORF37deficient patients have been diagnosed with BBS (Heon et al., 2016; Khan et al., 2016); one carried a benign BBS4 heterozygous mutation (Heon et al., 2016) and the other carried a mutation exactly the same as in other four patients with CRD (EstradaCuzcano et al., 2012; Lazar et al., 2014; Khan et al., 2016). Therefore, it is possible that the non-ocular phenotype of C8ORF37 mutations is modified by other genes or is not fully penetrant.
Alternatively, there may be a species difference for the requirement of C8ORF37 in non-ocular tissues, which has been documented for other BBS-associated mutations (Novas et al., 2015).

A critical observation at the molecular level is that C8orf $37 \mathrm{KO}$ results in a variable reduction in the expression levels of several proteins known to participate in the process of photoreceptor disc morphogenesis. For example, at P30, PRPH2, CNGB1, and GARP2 were present at $\sim 50 \%$ of the level seen in C8orf $37^{+/ \mathrm{del}}$ mice, whereas PCDH21 was not reduced at all. Furthermore, rhodopsin, the major OS disc building block protein, was reduced by only $\sim 29 \%$. Therefore, a mismatch in the molar ratio exists among these critical proteins. The fact that such a mismatch can lead to abnormal photoreceptor morphology has been established in several previous studies. For example, OS disc misalignment similar to that observed in our study was documented in photoreceptors expressing a single copy of the PRPH2 gene (Hawkins et al., 1985; Chakraborty et al., 2014). Long stacks of misaligned discs were also found in $\mathrm{Cngb1}^{-/-}$photoreceptors, where no CNGB1 and GARP2 were expressed (Zhang et al., 2009; Chakraborty et al., 2016). The larger reduction of PRPH2, CNGB1, and GARP2 proteins than rhodopsin in C8orf37 KO photoreceptors may explain the observed OS disc overgrowth and vertical alignment.

How could a cytoplasmic protein coordinate the relative expression levels of multiple OS membrane proteins? A previous study of c8orf37 knock-down zebrafish suggested a role of C8ORF37 in melanosome transport (Heon et al., 2016). However, our observation that OS localization of all tested membrane proteins in rods was unaffected by the C8ORF37 KO argues against its involvement in motor-mediated protein transport. Because the majority of proteins affected by the loss of C8orf37 are membrane proteins and the mRNA levels of these membrane proteins are initially normal, C8ORF37 likely functions in the membrane protein secretory pathway, from synthesis to sorting. One possibility is that C8ORF37 serves as a part of the molecular chaperone machinery that assists the final folding stages of multiple proteins affected by the loss of C8orf37. Alternatively, C8ORF37 may function by preventing these proteins from entering degradation pathways in the photoreceptor cell body. The variation in the decreased levels of OS membrane proteins in the absence of C8ORF37 may be due to the difference in their individual degradation rates. Sorting out these and other potential functions of C8ORF37 is an exciting goal of future investigations.

The earliest phenotype observed in C8orf37 KO photoreceptors is the reduction of rhodopsin content at P5. This may suggest that the observed reduction in the expression levels of PRPH2, CNGB1, and GARP2 is a consequence of rhodopsin reduction. However, the previously published phenotype of $R h o^{+/-}$mouse rods argues against this idea. $R h o^{+l-}$ rods contain $\sim 50 \%$ of the normal amount of rhodopsin (Lem et al., 1999; Price et al., 2012; Chakraborty et al., 2016); however, their PRPH2 content is normal (Chakraborty et al., 2016), their OS are thinner and shorter, and their disc alignment is normal (Lem et al., 1999; Liang et al., 2004; Price et al., 2012; Hollingsworth and Gross, 2013). Therefore, the difference in the $R h o^{+1-}$ and C8orf37 KO phenotypes indicates that the reduction of other OS membrane proteins in C8orf37 KO photoreceptors does not rely on the reduction of rhodopsin and is a primary defect as well.

The phenotypes in C8orf37 KO rod and cone photoreceptors are different. Whereas CNGB1 is reduced in rods, its counterpart CNGB3 remains normal in cones. Compared with rhodopsin protein reduction, cone opsin protein reduction occurs at a later time point but is more severe in adulthood. Furthermore, visual 
pigment mislocalization in cones is not observed in rods. All these results hint at the existence of differences in the intracellular processing of OS membrane proteins in rod and cone photoreceptors and a potential difference in their C8ORF37-dependent control.

In summary, the C8orf37 KO mouse generated in our study provides an accurate representation of the retinal phenotype in patients and is a valid animal model for future pathophysiological and therapeutic studies. We demonstrated that C8ORF37 is a protein expressed throughout the photoreceptor cell body and is required for maintaining physiological levels of OS membrane proteins. Loss of C8ORF37 leads to misalignment of photoreceptor OS discs and subsequent retinal degeneration. This degeneration is progressive and has a sufficient time window for therapeutic intervention.

\section{References}

Arikawa K, Molday LL, Molday RS, Williams DS (1992) Localization of peripherin/rds in the disk membranes of cone and rod photoreceptors: relationship to disk membrane morphogenesis and retinal degeneration. J Cell Biol 116:659-667. CrossRef Medline

Caley DW, Johnson C, Liebelt RA (1972) The postnatal development of the retina in the normal and rodless CBA mouse: a light and electron microscopic study. Am J Anat 133:179-212. CrossRef Medline

Chakraborty D, Conley SM, Al-Ubaidi MR, Naash MI (2014) Initiation of rod outer segment disc formation requires RDS. PLoS One 9:e98939. CrossRef Medline

Chakraborty D, Conley SM, Pittler SJ, Naash MI (2016) Role of RDS and rhodopsin in Cngb1-related retinal degeneration. Invest Ophthalmol Vis Sci 57:787-797. CrossRef Medline

Cong L, Ran FA, Cox D, Lin S, Barretto R, Habib N, Hsu PD, Wu X, Jiang W, Marraffini LA, Zhang F (2013) Multiplex genome engineering using CRISPR/Cas systems. Science 339:819-823. CrossRef Medline

De Robertis E (1956) Morphogenesis of the retinal rods; an electron microscope study. J Biophys Biochem Cytol 2:209-218. CrossRef Medline

Ding XQ, Nour M, Ritter LM, Goldberg AF, Fliesler SJ, Naash MI (2004) The R172W mutation in peripherin/rds causes a cone-rod dystrophy in transgenic mice. Hum Mol Genet 13:2075-2087. CrossRef Medline

Estrada-Cuzcano A, Neveling K, Kohl S, Banin E, Rotenstreich Y, Sharon D, Falik-Zaccai TC, Hipp S, Roepman R, Wissinger B, Letteboer SJ, Mans DA, Blokland EA, Kwint MP, Gijsen SJ, van Huet RA, Collin RW, Scheffer H, Veltman JA, Zrenner E; European Retinal Disease Consortium, et al. (2012) Mutations in C8orf37, encoding a ciliary protein, are associated with autosomal-recessive retinal dystrophies with early macular involvement. Am J Hum Genet 90:102-109. CrossRef Medline

Filipek S, Stenkamp RE, Teller DC, Palczewski K (2003) G protein-coupled receptor rhodopsin: a prospectus. Annu Rev Physiol 65:851-879. CrossRef Medline

Hartong DT, Berson EL, Dryja TP (2006) Retinitis pigmentosa. Lancet 368: 1795-1809. CrossRef Medline

Hawkins RK, Jansen HG, Sanyal S (1985) Development and degeneration of retina in rds mutant mice: photoreceptor abnormalities in the heterozygotes. Exp Eye Res 41:701-720. CrossRef Medline

Heitzmann H (1972) Rhodopsin is the predominant protein of rod outer segment membranes. Nat New Biol 235:114. Medline

Heon E, Kim G, Qin S, Garrison JE, Tavares E, Vincent A, Nuangchamnong N, Scott CA, Slusarski DC, Sheffield VC (2016) Mutations in C8ORF37 cause bardet biedl syndrome (BBS21). Hum Mol Genet 25:2283-2294. CrossRef Medline

Hollingsworth TJ, Gross AK (2013) The severe autosomal dominant retinitis pigmentosa rhodopsin mutant Ter349Glu mislocalizes and induces rapid rod cell death. J Biol Chem 288:29047-29055. CrossRef Medline

Hwang WY, Fu Y, Reyon D, Maeder ML, Tsai SQ, Sander JD, Peterson RT, Yeh JR, Joung JK (2013) Efficient genome editing in zebrafish using a CRISPR-cas system. Nat Biotechnol 31:227-229. CrossRef Medline

Jinda W, Taylor TD, Suzuki Y, Thongnoppakhun W, Limwongse C, Lertrit P, Suriyaphol P, Trinavarat A, Atchaneeyasakul LO (2014) Whole exome sequencing in thai patients with retinitis pigmentosa reveals novel mutations in six genes. Invest Ophthalmol Vis Sci 55:2259-2268. CrossRef Medline

Katagiri S, Hayashi T, Yoshitake K, Akahori M, Ikeo K, Gekka T, Tsuneoka H,
Iwata T (2016) Novel C8orf37 mutations in patients with early-onset retinal dystrophy, macular atrophy, cataracts, and high myopia. Ophthalmic Genet 37:68-75. Medline

Khan AO, Decker E, Bachmann N, Bolz HJ, Bergmann C (2016) C8orf37 is mutated in Bardet-Biedl syndrome and constitutes a locus allelic to nonsyndromic retinal dystrophies. Ophthalmic Genet 37:290-293. CrossRef Medline

Lazar CH, Mutsuddi M, Kimchi A, Zelinger L, Mizrahi-Meissonnier L, Marks-Ohana D, Boleda A, Ratnapriya R, Sharon D, Swaroop A, Banin E (2014) Whole exome sequencing reveals GUCY2D as a major gene associated with cone and cone-rod dystrophy in israel. Invest Ophthalmol Vis Sci 56:420-430. CrossRef Medline

Lem J, Krasnoperova NV, Calvert PD, Kosaras B, Cameron DA, Nicolò M, Makino CL, Sidman RL (1999) Morphological, physiological, and biochemical changes in rhodopsin knockout mice. Proc Natl Acad Sci U S A 96:736-741. CrossRef Medline

Liang Y, Fotiadis D, Maeda T, Maeda A, Modzelewska A, Filipek S, Saperstein DA, Engel A, Palczewski K (2004) Rhodopsin signaling and organization in heterozygote rhodopsin knockout mice. J Biol Chem 279:48189 48196. CrossRef Medline

Liu Q, Lyubarsky A, Skalet JH, Pugh EN Jr, Pierce EA (2003) RP1 is required for the correct stacking of outer segment discs. Invest Ophthalmol Vis Sci 44:4171-4183. CrossRef Medline

Liu X, Bulgakov OV, Wen XH, Woodruff ML, Pawlyk B, Yang J, Fain GL, Sandberg MA, Makino CL, Li T (2004) AIPL1, the protein that is defective in leber congenital amaurosis, is essential for the biosynthesis of retinal rod cGMP phosphodiesterase. Proc Natl Acad Sci U S A 101: 13903-13908. CrossRef Medline

Lobanova ES, Finkelstein S, Herrmann R, Chen YM, Kessler C, Michaud NA, Trieu LH, Strissel KJ, Burns ME, Arshavsky VY (2008) Transducin gamma-subunit sets expression levels of alpha- and beta-subunits and is crucial for rod viability. J Neurosci 28:3510-3520. CrossRef Medline

Mali P, Yang L, Esvelt KM, Aach J, Guell M, DiCarlo JE, Norville JE, Church GM (2013) RNA-guided human genome engineering via Cas9. Science 339:823-826. CrossRef Medline

Matsuda T, Cepko CL (2004) Electroporation and RNA interference in the rodent retina in vivo and in vitro. Proc Natl Acad Sci U S A 101:16-22. CrossRef Medline

Mitamura Y, Mitamura-Aizawa S, Nagasawa T, Katome T, Eguchi H, Naito T (2012) Diagnostic imaging in patients with retinitis pigmentosa. J Med Invest 59:1-11. CrossRef Medline

Molday RS (1998) Photoreceptor membrane proteins, phototransduction, and retinal degenerative diseases. the friedenwald lecture. Invest Ophthalmol Vis Sci 39:2491-2513. Medline

Novas R, Cardenas-Rodriguez M, Irigoín F, Badano JL (2015) Bardet-Biedl syndrome: is it only cilia dysfunction? FEBS Lett 589:3479-3491. CrossRef Medline

Pearring JN, Salinas RY, Baker SA, Arshavsky VY (2013) Protein sorting, targeting and trafficking in photoreceptor cells. Prog Retin Eye Res 36: 24-51. CrossRef Medline

Poetsch A, Molday LL, Molday RS (2001) The cGMP-gated channel and related glutamic acid-rich proteins interact with peripherin-2 at the rim region of rod photoreceptor disc membranes. J Biol Chem 276:4800948016. CrossRef Medline

Price BA, Sandoval IM, Chan F, Nichols R, Roman-Sanchez R, Wensel TG, Wilson JH (2012) Rhodopsin gene expression determines rod outer segment size and rod cell resistance to a dominant-negative neurodegeneration mutant. PLoS One 7:e49889. CrossRef Medline

Rahner N, Nuernberg G, Finis D, Nuernberg P, Royer-Pokora B (2016) A novel C8orf37 splice mutation and genotype-phenotype correlation for cone-rod dystrophy. Ophthalmic Genet 37:294-300. CrossRef Medline

Rattner A, Smallwood PM, Williams J, Cooke C, Savchenko A, Lyubarsky A, Pugh EN, Nathans J (2001) A photoreceptor-specific cadherin is essential for the structural integrity of the outer segment and for photoreceptor survival. Neuron 32:775-786. CrossRef Medline

Ravesh Z, El Asrag ME, Weisschuh N, McKibbin M, Reuter P, Watson CM, Baumann B, Poulter JA, Sajid S, Panagiotou ES, O'Sullivan J, Abdelhamed Z, Bonin M, Soltanifar M, Black GC, Amin-ud Din M, Toomes C, Ansar $\mathrm{M}$, Inglehearn CF, Wissinger B, et al. (2015) Novel C8orf37 mutations cause retinitis pigmentosa in consanguineous families of pakistani origin. Mol Vis 21:236-243. Medline 
Robinson WE, Gordon-Walker A, Bownds D (1972) Molecular weight of frog rhodopsin. Nat New Biol 235:112-114. Medline

Sander JD, Zaback P, Joung JK, Voytas DF, Dobbs D (2007) Zinc finger targeter (ZiFiT): an engineered zinc finger/target site design tool. Nucleic Acids Res 35:W599-605. CrossRef Medline

Sander JD, Maeder ML, Reyon D, Voytas DF, Joung JK, Dobbs D (2010) ZiFiT (Zinc finger Targeter): an updated zinc finger engineering tool. Nucleic Acids Res 38:W462-468. CrossRef Medline

Sanyal S, Dees C, Zeilmaker GH (1986) Development and degeneration of retina in rds mutant mice: observations in chimaeras of heterozygous mutant and normal genotype. J Embryol Exp Morphol 98:111-121. Medline

Sokolov M, Lyubarsky AL, Strissel KJ, Savchenko AB, Govardovskii VI, Pugh EN Jr, Arshavsky VY (2002) Massive light-driven translocation of transducin between the two major compartments of rod cells: a novel mechanism of light adaptation. Neuron 34:95-106. CrossRef Medline

Sokolov M, Strissel KJ, Leskov IB, Michaud NA, Govardovskii VI, Arshavsky VY (2004) Phosducin facilitates light-driven transducin translocation in rod photoreceptors: evidence from the phosducin knockout mouse. J Biol Chem 279:19149-19156. CrossRef Medline

Stadler C, Rexhepaj E, Singan VR, Murphy RF, Pepperkok R, Uhlén M, Simpson JC, Lundberg E (2013) Immunofluorescence and fluorescent-protein tagging show high correlation for protein localization in mammalian cells. Nat Methods 10:315-323. CrossRef Medline

Thiadens AA, Phan TM, Zekveld-Vroon RC, Leroy BP, van den Born LI, Hoyng CB, Klaver CC, Klaver CC, Roosing S, Pott JW, van Schooneveld MJ, van Moll-Ramirez N, van Genderen MM, Boon CJ, den Hollander AI, Bergen AA, De Baere E, Cremers FP, Lotery AJ (2012) Clinical course, genetic etiology, and visual outcome in cone and cone-rod dystrophy. Ophthalmology 119:819-826. CrossRef Medline

van Huet RA, Estrada-Cuzcano A, Banin E, Rotenstreich Y, Hipp S, Kohl S, Hoyng CB, den Hollander AI, Collin RW, Klevering BJ (2013) Clinical characteristics of rod and cone photoreceptor dystrophies in patients with mutations in the C8orf37 gene. Invest Ophthalmol Vis Sci 54:4683-4690. CrossRef Medline

Wang L, Zou J, Shen Z, Song E, Yang J (2012) Whirlin interacts with espin and modulates its actin-regulatory function: an insight into the mechanism of usher syndrome type II. Hum Mol Genet 21:692-710. CrossRef Medline

Wrigley JD, Ahmed T, Nevett CL, Findlay JB (2000) Peripherin/rds influ- ences membrane vesicle morphology: implications for retinopathies. J Biol Chem 275:13191-13194. CrossRef Medline

Xiao A, Cheng Z, Kong L, Zhu Z, Lin S, Gao G, Zhang B (2014) CasOT: a genome-wide Cas9/gRNA off-target searching tool. Bioinformatics 30 : 1180-1182. CrossRef Medline

Yang J, Liu X, Yue G, Adamian M, Bulgakov O, Li T (2002) Rootletin, a novel coiled-coil protein, is a structural component of the ciliary rootlet. J Cell Biol 159:431-440. CrossRef Medline

Yang J, Gao J, Adamian M, Wen XH, Pawlyk B, Zhang L, Sanderson MJ, Zuo J, Makino CL, Li T (2005) The ciliary rootlet maintains long-term stability of sensory cilia. Mol Cell Biol 25:4129-4137. CrossRef Medline

Yang RB, Robinson SW, Xiong WH, Yau KW, Birch DG, Garbers DL (1999) Disruption of a retinal guanylyl cyclase gene leads to cone-specific dystrophy and paradoxical rod behavior. J Neurosci 19:5889-5897. Medline

Yang Z, et al. (2008) Mutant prominin 1 found in patients with macular degeneration disrupts photoreceptor disk morphogenesis in mice. J Clin Invest 118:2908-2916. CrossRef Medline

Young RW (1967) The renewal of photoreceptor cell outer segments. J Cell Biol 33:61-72. CrossRef Medline

Zacchigna S, Oh H, Wilsch-Bräuninger M, Missol-Kolka E, Jászai J, Jansen S, Tanimoto N, Tonagel F, Seeliger M, Huttner WB, Corbeil D, Dewerchin M, Vinckier S, Moons L, Carmeliet P (2009) Loss of the cholesterolbinding protein prominin-1/CD133 causes disk dysmorphogenesis and photoreceptor degeneration. J Neurosci 29:2297-2308. CrossRef Medline

Zaghloul NA, Katsanis N (2009) Mechanistic insights into Bardet-Biedl syndrome, a model ciliopathy. J Clin Invest 119:428-437. CrossRef Medline

Zhang Y, Molday LL, Molday RS, Sarfare SS, Woodruff ML, Fain GL, Kraft TW, Pittler SJ (2009) Knockout of GARPs and the beta-subunit of the rod cGMP-gated channel disrupts disk morphogenesis and rod outer segment structural integrity. J Cell Sci 122:1192-1200. CrossRef Medline

Zhao Y, Hong DH, Pawlyk B, Yue G, Adamian M, Grynberg M, Godzik A, Li T (2003) The retinitis pigmentosa GTPase regulator (RPGR)- interacting protein: subserving RPGR function and participating in disk morphogenesis. Proc Natl Acad Sci U S A 100:3965-3970. CrossRef Medline

Zou J, Luo L, Shen Z, Chiodo VA, Ambati BK, Hauswirth WW, Yang J (2011) Whirlin replacement restores the formation of the USH2 protein complex in whirlin knockout photoreceptors. Invest Ophthalmol Vis Sci 52:23432351. CrossRef Medline 